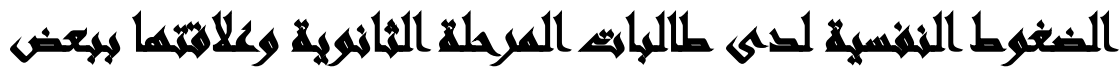

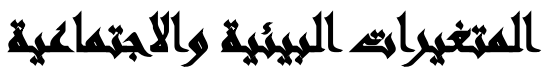

[11]

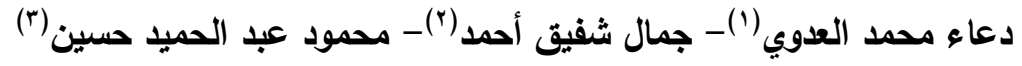

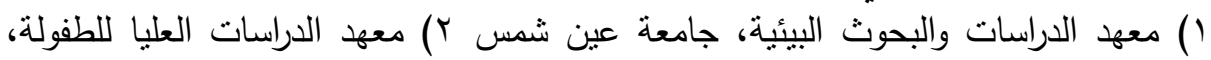

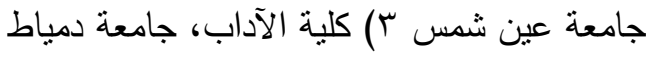

\section{المستخليس}

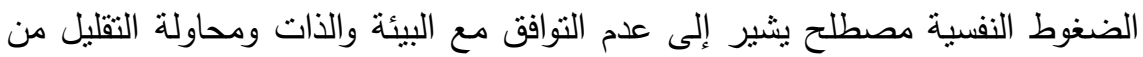

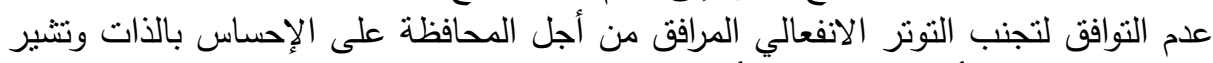

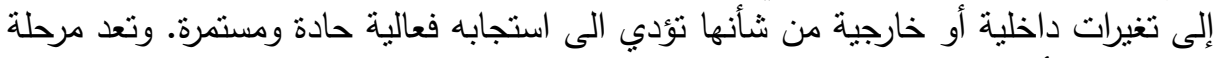

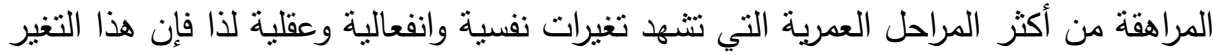
يؤدي الى الضغط النفسي.

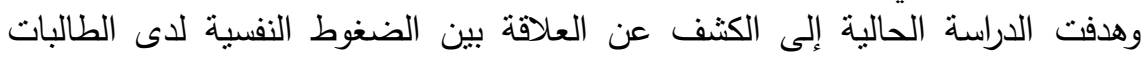

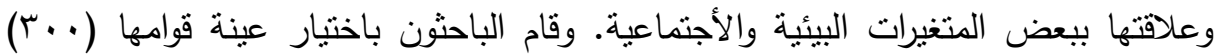

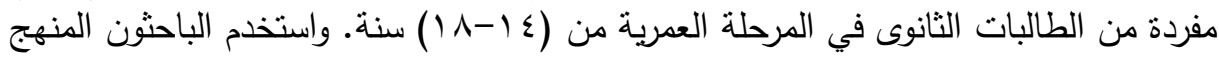

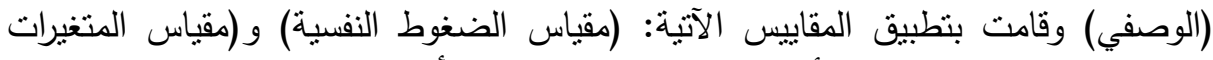

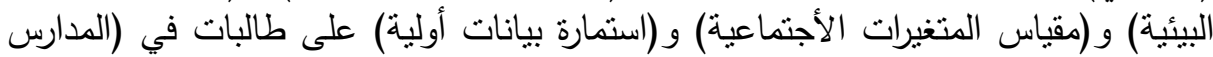

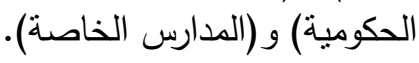

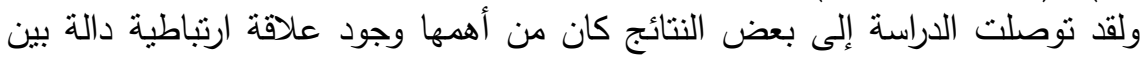

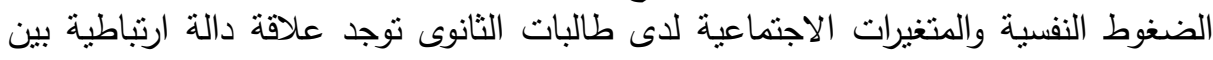
الضغوط النفسية والمتغيرات البيئية لدى طالبات النيات الثانوى.

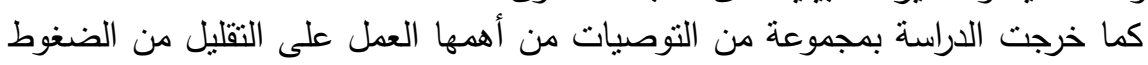

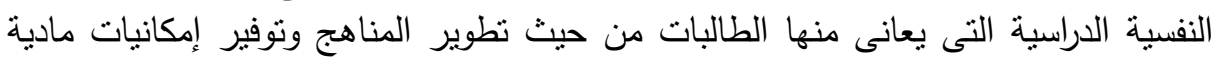

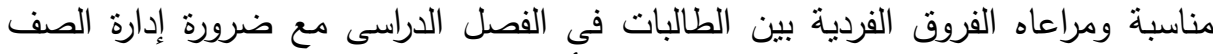

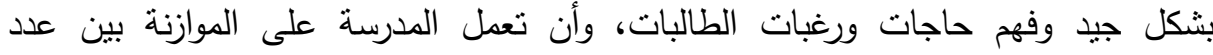

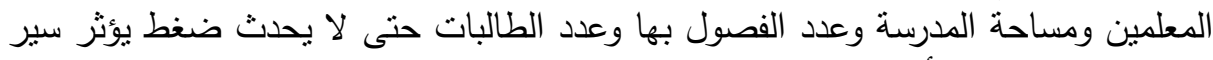
العملية التعليمية وفق أهدافها. 


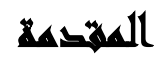

يتعرض الإنسان فى حياته للعديد من المواقف الصعبة والأحداث التى تقابله وتؤثر على الصى

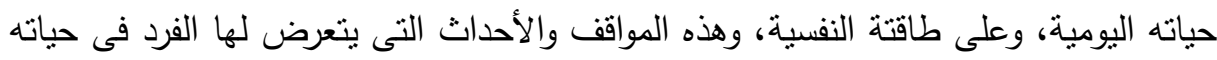

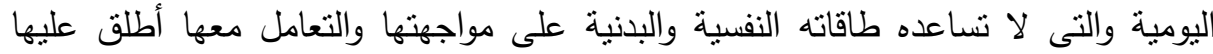
الباحثون (الضغوط). هذا إذا أخذنا الضغط النفسى من جانبه السلبى، أما إذا نظرنا إليه من الئه

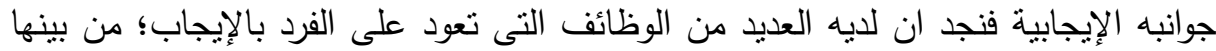

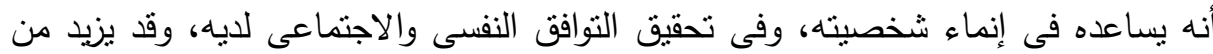
درجة انتاجه العلمى والعملى فى الحياة، وكذا من نجاحاته وتطلعاته ومستوى طموحاته. ونظراً لما ينعرض له الطالب اليوم من ضغوط وما يواجهه من صعاب ومشكلات لمقابلة منطلبات العصر الذى طرأ عليه الكثير من المستجدات فى مختلف المجالات التعليمية والتكنولوجية

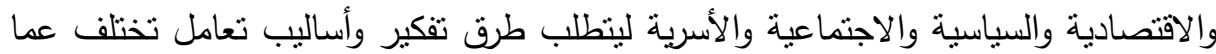

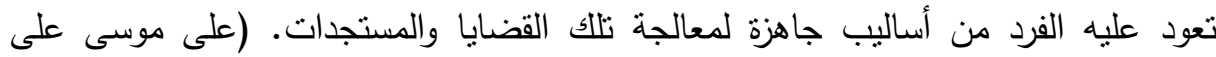

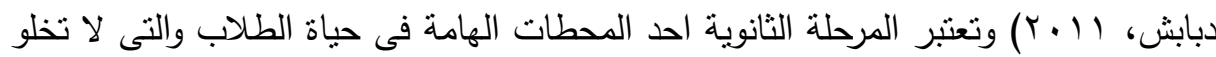
من نلك الضغوط والإحداث والمواقف والأزمات اليومية الضاغطة. وهذه الضغوط لهان لها أثارها

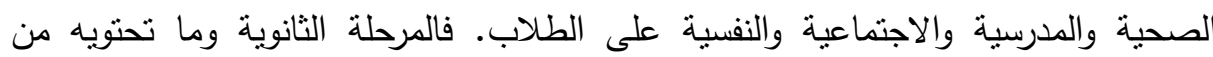
متغيرات ومتطلبات تجعل الطلاب أمام مواجهة للعديد من الصعاب والمواقف والتنى تتطلب الطابل

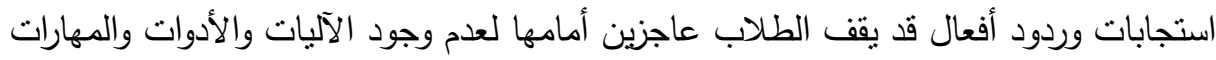

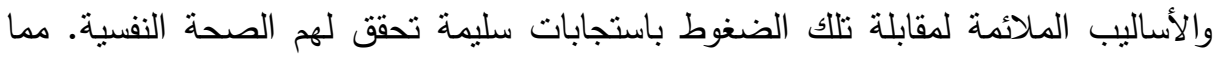

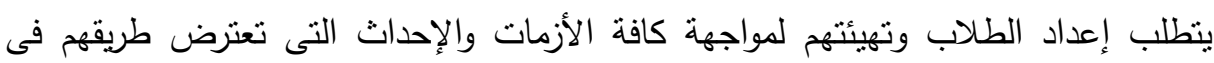

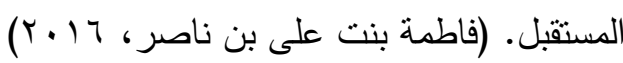

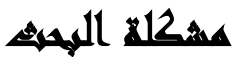

تواجه الطالبات فى مختلف المراحل الدراسية ومنهن طالبات المرحلة الثانوية العديد من التحديات والضغوط النفسية التى قد نكون ناجمة عن العديد من العوامل كالخوف من المستقبل وصعوبة الاتصال مع الآخرين ومطالبة الأسرة والمجتمع لهم بتحقيق النجاح بل التنفو؛؛ لأن 
هذه المرحلة هى مرحلة تحديد مصير الطالبات المتعلقة بالحياة الجامعية إضافة إلى ما يحدث فى هذه المرحلة من تغيرات جسمية وهرمونية تؤدى إلى حدوث العديد من مشاكل النمو . وما لم يعالج الضغط الذى تتعرض له الطالبات بشكل ناجح فقد تطفو على السطح مشاعر الوحدة والعصبية بالإضافة إلى قلة النوم والقلق المفرط فالضغوط النفسية لها أثز كبير على التحصيل

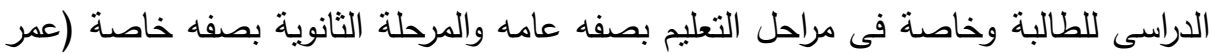
مصلحى، مستور السهلى: 10 × ب) حيث أنها مرحلة دراسية مصيرية تحدد إلى حد كبير مستقبل الفتاة فى سنوات عمرها المقبلة فهى بداية طريق الاختيار واتخاذ القرارات المصيرية وهى مرحلة دراسية نتزامن مع مرحلة المراهقة تلك المرحلة تتسم بالتقلبات الانفعالية والفكرية وتتسم بالتمرد والعصيان ومحاولة إثبات الذات من خلال مخالفة كل ما هو سائد ومطلوب لدى الأسرة أو المجتمع. ولقد أجريت مختلف المحاولات للتحقق من العوامل التى تهيئ الأفراد للضغوط النفسية ومن تلك المحاولات التى ربطت بين حدوث الضغوط وشخصية الأفراد، دراسة (2000) Akimbo and Adeyemo التى أظهرت أن بعض الأفراد أكثر عرضة للضغوط النفسية بصفة عامة، بينما الآخرين أقل عرضة للضغوط اعتمادا على سماتهر الثخصية، جاءت هذه النتائج مطابقة لنتائج الثخصية بالضغوط النفسية وتنثير نتائج العديد من الدراسات إلى أن هناك ثمة علاقة Haley Van Barker ارتباطية موجبة بين الضغوط النفسية وبعض سمات الثخصية دراسة (2009) فى حين أظهرت بعض النتائج عدم وجود أى علاقة بين الضغوط النفسية وبعض

سمات الشخصية (2010) Pocola \& Ilugbo. إن وجود الكثير من الضغوط والأزمات النفسية والانفعالية لدى طالبات مرحلة الثنانوية العامة يتسبب فى الهرر التربوى المتمتل فى عدم استفادة الطالبات من نظام التعليم وتكرار الرسوب أو الإعادة أو التسرب من التعليم مما ينتج عنه الكثير من المشكلات الاجتماعية والصحية التى تؤثر فى المجتمع بأسره وأكثر المشكلات نأثيرا على الطالبات الكأبه وسببها الضغط النفسى الكبير الذى تعانبه الطالبات بسبب الخوف من المجهول وتراود الطالبات فى بـ هذه الحاله خواطر كثيرة وخوف وشك وقله الثقة بالنفس وأحيانا انعدامها (أميرة سعيد عبد بدرد

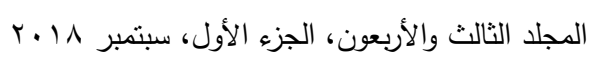




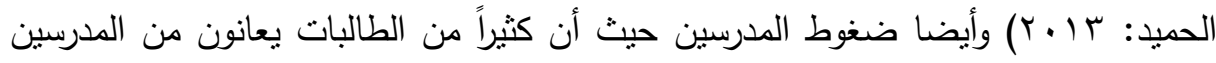
إما لقلة عددهم وقلة خبراتهم أو بسبب تعامل بعض المدرسين غير اللائق مع الطالبات وتخويفهن وهناك العديد من العناصر التى يجب الاعتماد عليها من أجل القضاء على ضغنوط لئل

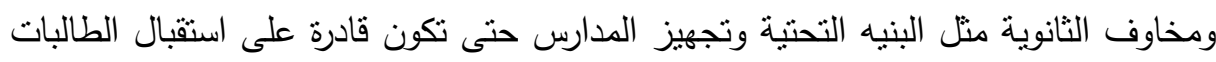

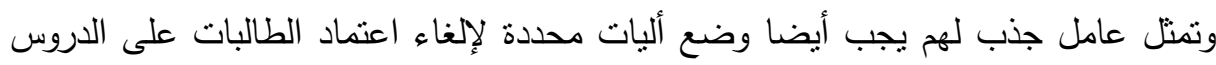

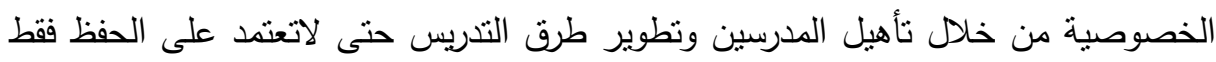

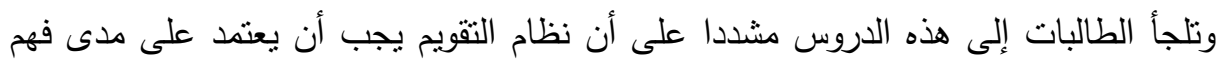

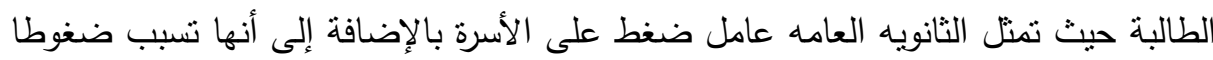

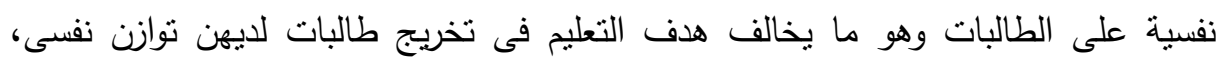

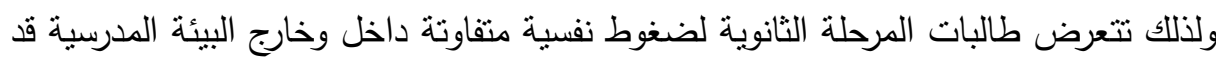
تترك آثاراً نفسية كبيرة على شخصياتهن وتوافقهن مع المجتمع المحيط كل ذلك ينعكس سلباً أو

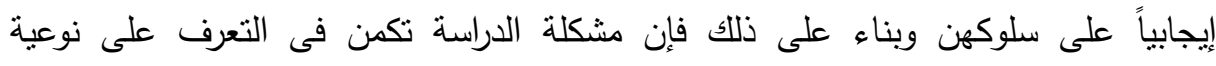
Akimbo and Ademo: ( الضغوط النفسية المتعددة والمدركة لاى طالبات المرحلة الثانويةه

\section{أهميه اللهيه}

الناحية النظرية: تتبع أهمية هذه الدراسة بمرحلة دراسية هامة وهى المرحلة الثانوية والتى تقابل مرحلة المراهقة (المرحلة الوسطى) والتى يكون فيها الطالبات بحاجة إلى إثباع حاجاتهم

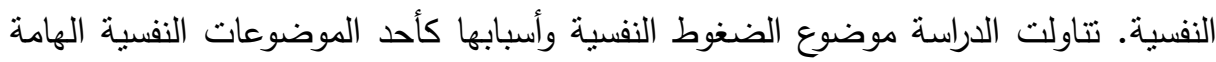
التى تحتاج إلى مزيد من الدراسات والبحوث فى الفترة الحالية. الناحية التطبيقية: محاولة التعرف على بعض المعلومات التى من خلاله يمكن أن تساعد طلاب المرحلة الثانوية ما يواجهونة من ضغوط. لمانه تتضح أهمية الدراسة الحالية إيجاد سبل ووسائل تطبيقية نساعد فى حل المشكلة وذلك فئل من أجل التوصل الى قواعد حديثة تربوية تناعد على فهم وليس الحفظ. 


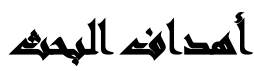

ا. التعرف على أنواع الضغوط النفسية المؤثرة على مستوى التحصيل الدراسى لدى طالبات

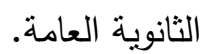

r. التعرف على علاقة الضغوط النفسية بالمتغيرات البيئية أثثاء التحصيل الدراسى لطالات الثانوية العامة.

r. التعرف على مشكلة الضغوط النفسية تأثيرها على الطالبات فى تحقيق أهدافهر ومنطالباتهم. ع. التعرف على أسباب الضغوط النفسية التى تعانى منها الطالبات. ه. تحديد مستوي الضغوط النفسية التى تعانى منها الطالبات فى كل من المدارس الحكومية

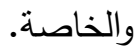

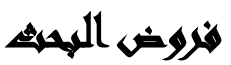

ا ـ توجد علاقة ارتباطية ذات دالة احصائياً بين الضغوط النفسية والمتغيرات الاجتماعبة لدى

$$
\text { طالبات الثانوي. }
$$

r. توجد علاقة ارتباطية ذات دالة احصائياً بين الضغوط النفسية والمتغيرات البيئية لدى طالبات الثانوي. r. توجد فروق ذات دلالة احصائية بين منوسطات درجات طالبات الثانوي لمقياس الضغوط النفسية تبعاً لمتغير الصف الدراسي.

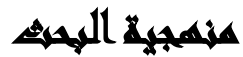

استخدمت الدراسة الحالية (المنهج الوصفى) وذلك لملائمته موضوع الدراسة الذى يهدف

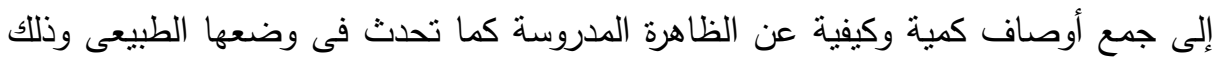

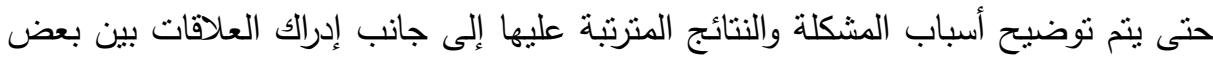

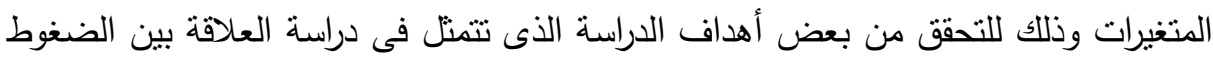

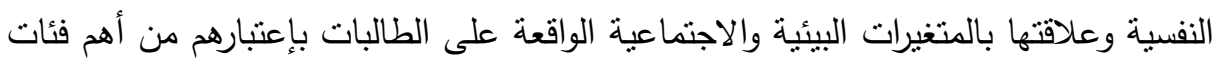

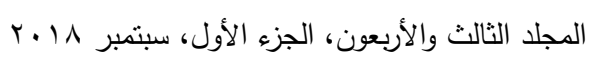


المجتمع إلى جانب اعتماده على المقارنة فى دراسة المشكلة المدروسة حيث ييرز أوجه الثببه والاختلاف فيما بين ظاهرتين أو أكثر من حيث الوقوف على الفروق بين هذه الفئات فى دى دراسه المدارس الحكومية والخاصة وتأثير ذلك على المستوى الدراسى. لاسن.

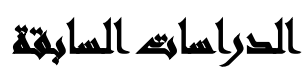

دراسة فاطمة بنت على بن ناصر (7 1 ـ ب) بعنوان الضغوط النفسية المدركة وأساليب التعامل معها لدى طالبات المرحلة الثانوية المتفوقات والمتأخرات دراسياً. تهدف الدراسة التعرف على مصادر الضغوط النفسية التى تعانى منها طالبات الثانوبة

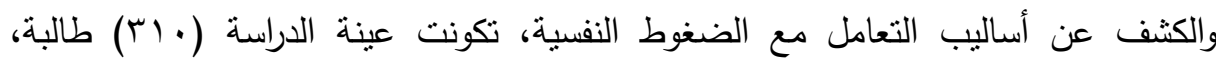
استخدم الباحث مقياس الضغط النفسي، استخدمت المنهج الوصفى المقارن. أشارت نتائج الدراسة لاتوجد فروق ذات دلالة إحصائية فى مستوى درجات الطالبات المنقوقات دراسياً

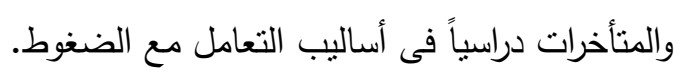

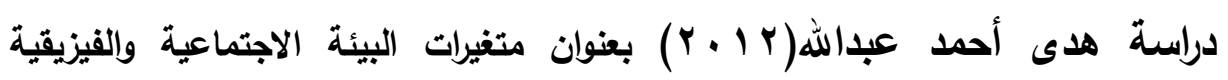
للمتسربين من التعليم. تهدف الدراسة فى تحديد أهم متغيرات البيئة الاجنماعية والبيئة الفيزيقية فى السكن

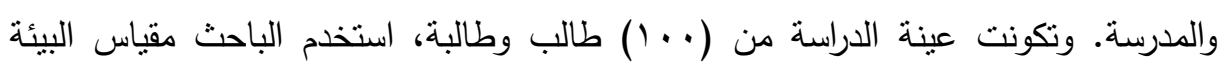
الفيزيقية والبيئة الاجتماعية. استخدم المنهج الوصفى. أوضحت نتائج الدراسة أن أكثر

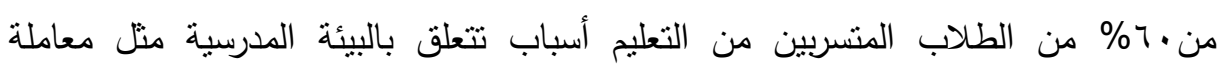
المعلمين السيئة وصعوبة المقررات الدراسية والمستوى الاقتصادى للأسرة. دراسة ليل كيليماري Lyell, KellyMarie (2012) بعنوان الدعم الاجتماعي والتوافق النفسي بمرحلة المراهقة. هدفت الدراسة إلى الوقوف علي علاقة الدعم الاجتماعي المقدم من الآباء والأمهات

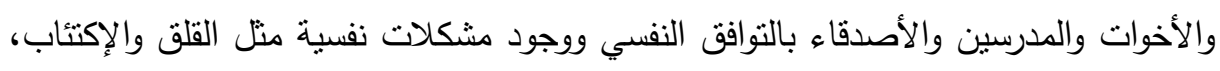

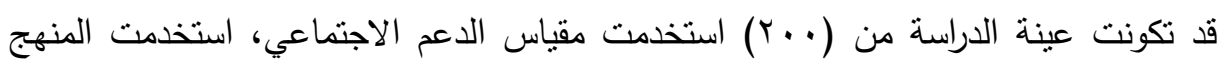
الوصفي المقارن، توصلت إلى أن هنالك فروق بين الجنسين في العلاقة بين الدعم الاجتماعي الأني

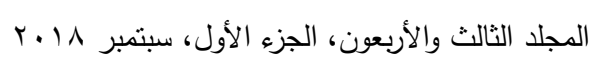


وأعراض القلق والأكتئاب بالنسية للإناث وعوامل الأكتئاب والقلق فإن (الأم وزملاء الفصل)

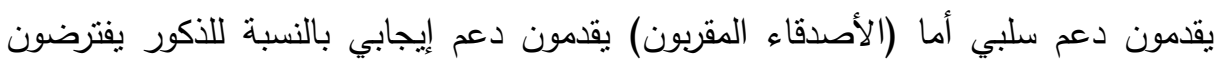

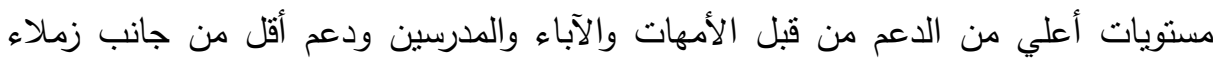

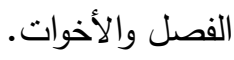

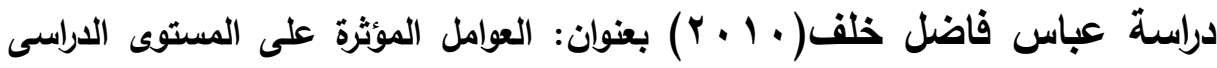

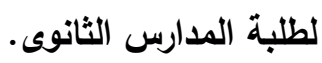

تهذف الدراسة التعرف على العوامل المؤثرة على المستوى الدراسى لطلبة الددارس

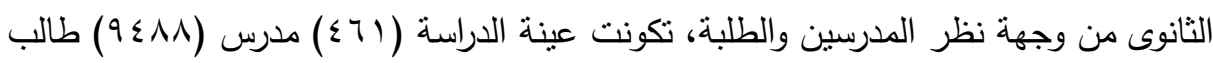

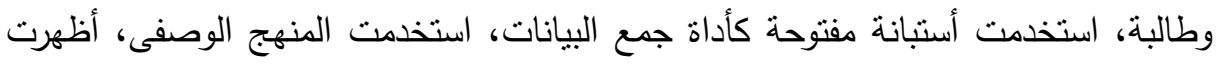

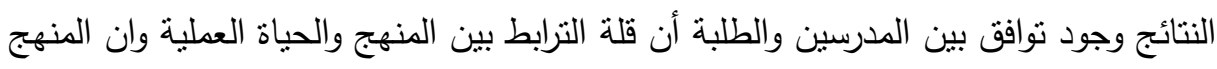

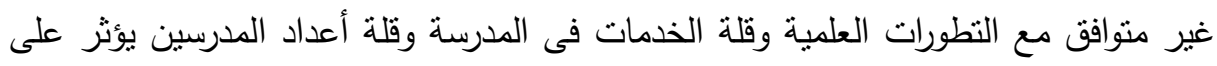

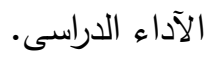

دراسة (2009) (201) \& Anshel, بنوان مصادر الضغط النفسي لاى الطلاب.

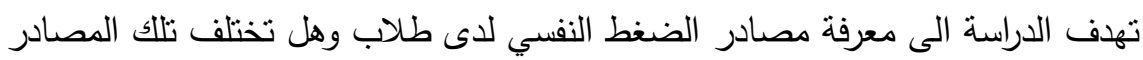

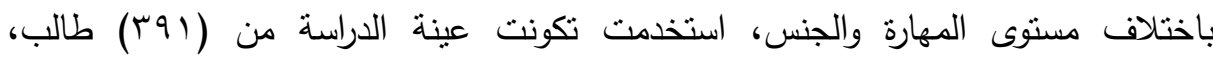

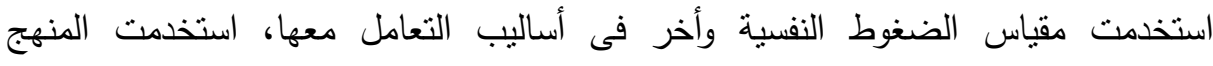

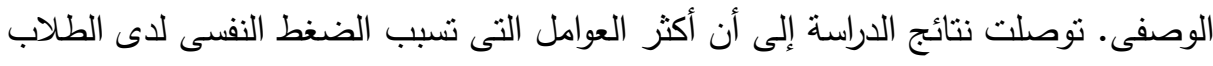

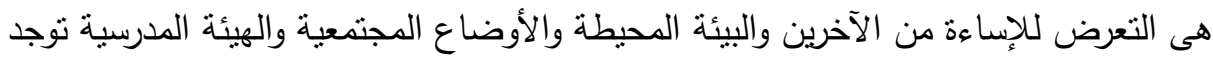
علاقة بين النحصيل الدراسى و الضغوط النفسية. التعليق على الدراسات السابقة: انققت الدراسات مع أهداف الدراسة الحالية دراسة الكاسة

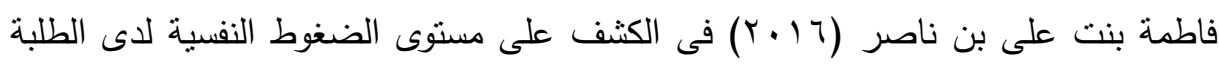
والتعرف على مصادرة والعوامل المسبية له لدى الطلبة وأيضا تأثير المنتيرات البيئية

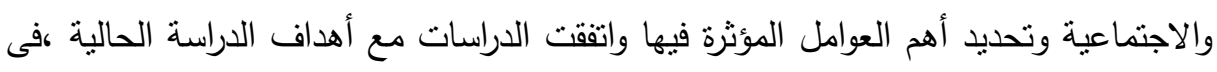

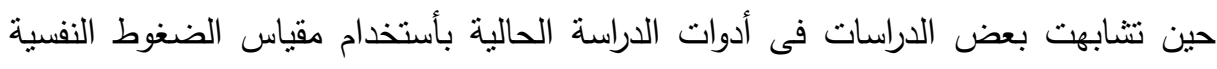

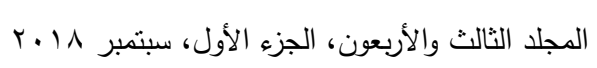


Gan \& Anshel, ومقياس المتغيرات البيئة ومقياس المتغيرات الاجتماعية منل دراسة

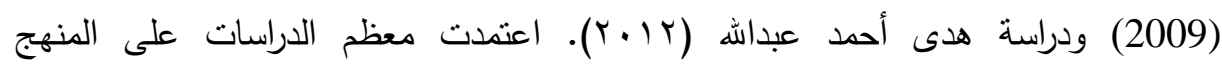

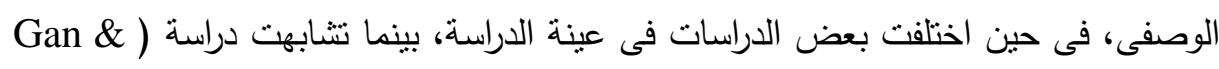

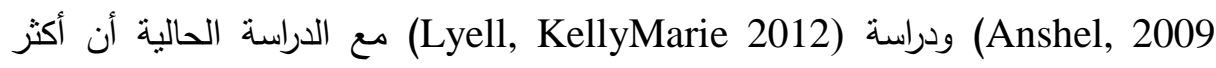
العوامل التى تنبب الضغط النفسى لدى الطلاب هى التعرض للإِساءة من الآخرين والبيئة

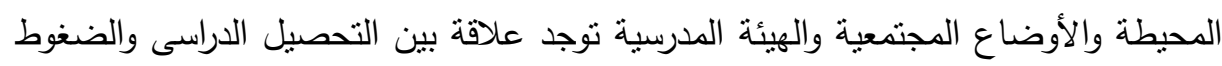
النفسية.

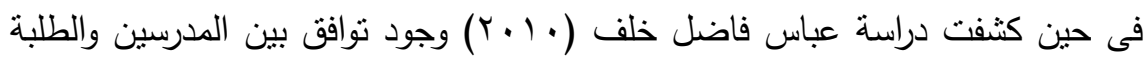
أن قلة الترابط بين المنهج والحياة العملية وان المنهج غير منوافق مع التطورات العلمية وقلة

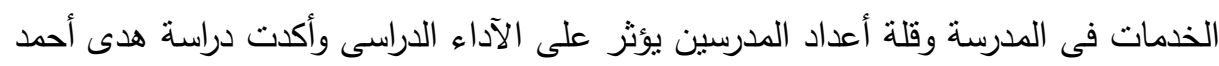

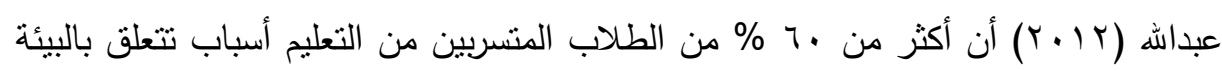

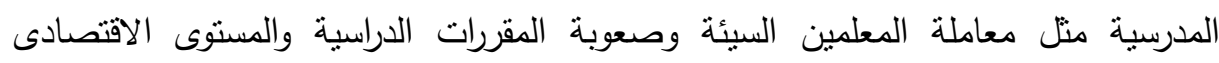
للأسرة، أفادت هذه الدراسات الدراسة الحالية فى بعض جوانب ولن الإطار النظرى المتعلق بالضغوط النفسية خاصة فى تحديد مصادر الضغوط النفسية المتمنلة فى البيئة المدرسية

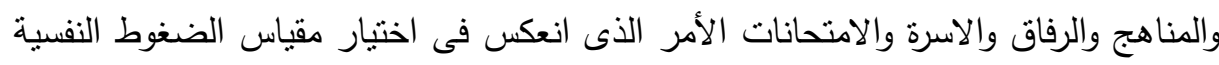

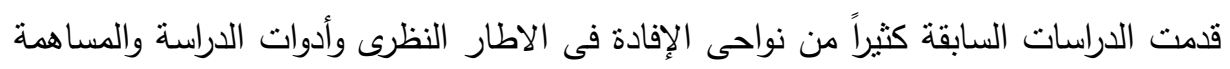
فى تحليل النتائج التى نم التوصل إليها.

\section{الإطار المعرهنى}

\section{مفاهيم البحث:}

الضغوط النفسية: تتمنت فى شعور الطالب بالفشل وقصور قدراته وإمكاناته فى استيعاب مناهجه الدراسية واستذكارها وشعوره بالنقص أمام التوقعات الوالدية خاصة بالنسبة لطلبة وفية

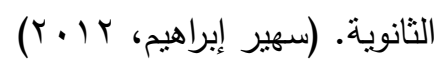


المتغيرات الاجتماعية: العامل المؤثر فى الحياة الاجتماعية والعلاقات الاجتماعية أو كل ما يتصل بالطالبات ويرتبط بتفاعلهم مع الآخرين ويطلق عليه أحياناً المتغيرات الاجتماعية بأنها المحددات الاجتماعية التى لها دور فى تشكيل البيئة. المتغيرات البيئية: يقصد بالمتغيرات البيئيه العوامل التى توجد في محيط التئه الطالبات التى تؤثز فى جميع جوانب حياتهم وأنماط سلوكهم وعلاقتها بالمعيشة وتقيم علاقات منبادلة ومتفاعلة وتؤثر على جوانب حياتهم المختلفة. المرحلة الثانوية: يقصد بها طلاب الصف الاولي وانثم الثانى والثالث ثانوى من التعليم العام وتعد الثانوية العامة المؤهل الرئيسى لاخول الجامعات ويمكن للطالب اختيار المواد التى يدرسها

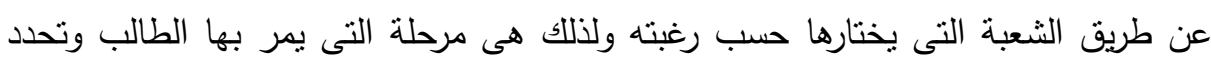
مصبره.

\section{الاجباءاهي المنمجية}

منهج البحث: تعد هذه الدراسة من الدراسات الوصفية الني تقوم على جمع الحقائق وتحليلها وتفسيرها لاستخلاص دلالتها وتصل بذلك لإصدار التعميمات بشأن الظاهرة موضوع الدراسة .

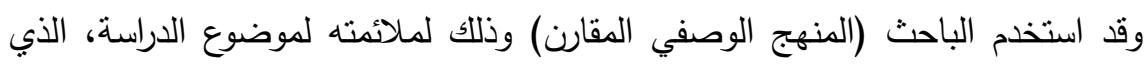
يهدف إلى جمع أوصاف كمية وكيفية عن الظاهرة المدروسة كما تحدث في وضعها الطبيعي. أدوات البحث: ضمت الأدوات المستخدمة في الدراسة الراهنة على ما يلي: • استمارة البيانات الأولية. (إعداد الباحثون) • • مقياس الضغوط النفسية. (إعداد الباحثون)

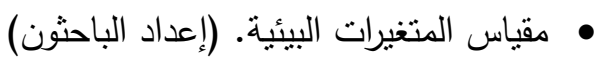
• مقياس المتغيرات الاجتماعية. (إعداد الباحثون) عينة البحث: اختيرت عينة التطبيق بالطريقة العشوائية وقد اشتملت عينة التطبيق على مجموعتين: 
• تم اختيار عينة النطبيق بالطريقة العشوائية (طالبات الثانوى العام) بمنطقة حدائق القبة التعليمية وبمنطقة الزاوية التعليمية.

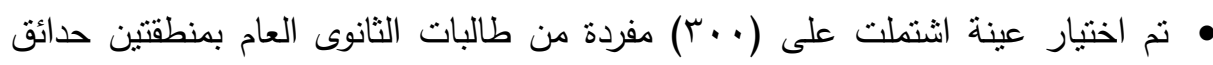

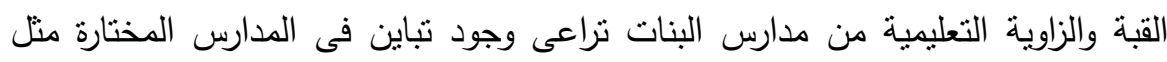
المدارس الحكومية والخاصة للاناث موزعين على مدارس مختلفة وفقا للوزن النسبى لكل

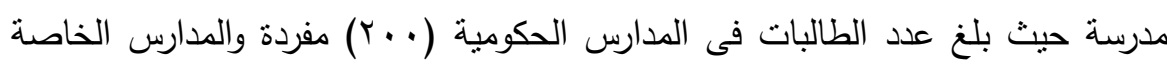
(1) (1) مفردة.

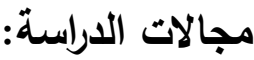

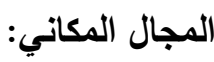

• تم إجراء الدراسة الميدانية ببعض المدارس الحكومية وتثمل مدرسة الحرية الثانوية بنات والسلام الثانوية بنات.

• وبعض المدارس الخاصة مدرسة الرياض الخاصة ومدرسة الإيمان الخاصة.

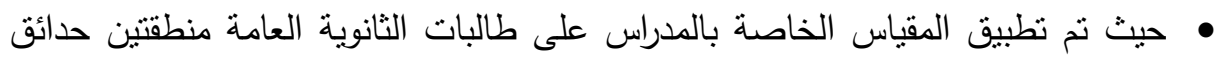
القبة والزاوية الحمراء.

المجال الزمني: مرت الدراسة بعدة مراحل في الفترات الزمنية الآتية : - المرحلة الأولى: والتى تم فيها الاطلاع على عدد من الدراسات السابقة التى تتاولت موضوع الدراسة ووضع الإطار النظرى الذى فسر مشكلة الدارسة والنظريات الموجهة لها. - المرحلة الثانية: اشتملت على إعداد الأدوات وعرض المقاييس على المحكمين وعمل تقنين للاختبارات (صدق وثبات) المقياس.

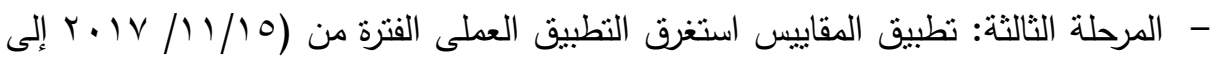

$$
\cdot(r \cdot) 1 / r / r \text {. }
$$

- المرحلة الرابعة: تفريغ البيانات وتحليل النتائج وتفسيرها ووضع توصيات ومقترحات الدراسة.

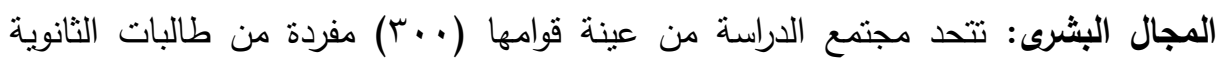

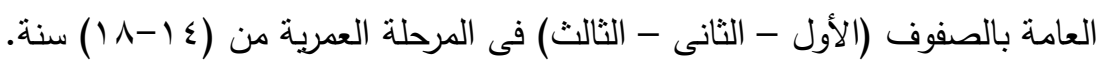


الأساليب الإحصائية: استخدمت الدراسة الأساليب الإحصائية الآتية: 1 ا ـ حساب الثبات من خلال معامل ألفا كرونباخ لاختبار ثبات المقياس.

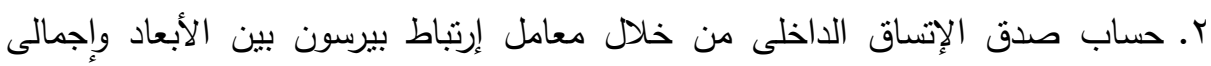

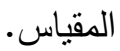
r. حساب العلاقات الإرتباطية بمعامل ارتباط بيرسون لأبعاد الدراسة للتحقق من صحة

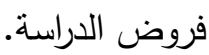

ـ. اختبار "ت" T-Test لتوضيح الفروق بين عينات الدراسة. ه. اختبار أنوفا ANOVA لتوضيح الفروق بين عينات الدراسة. ثبات وصدق مقياس الضغوط النفسية: قد قام الباحثون بإعداد مقياس الضغوط لثنات النفسية

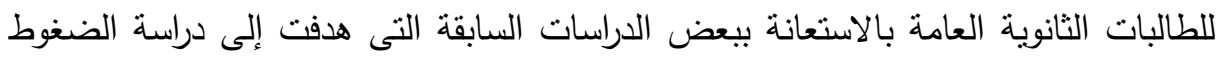

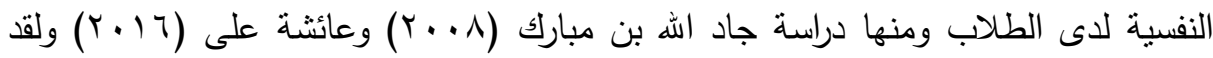
تتاول المقياس أربع أبعاد وهى (ضغوط العلاقات مع الاخرين) و (الضغوط الاقتصادية)

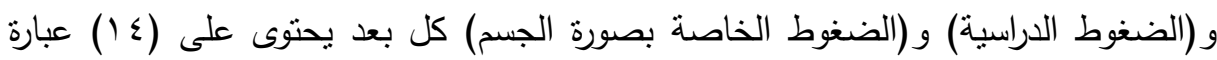

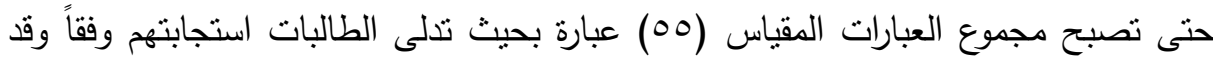

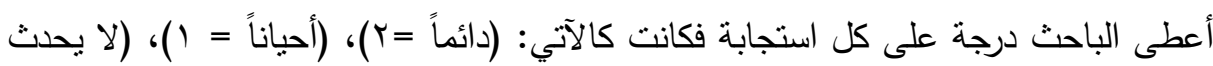

بالنسبة لحساب الثبات: للتحقق من ثبات المقياس استخدم الباحث معادلة ألفا كرونباخ (Cronbach Alpha) قيم معاملات الثبات لأبعاد مقياس الضغوط النفسية قيم مقبولة حيث بلغت قيم معامل الثبات

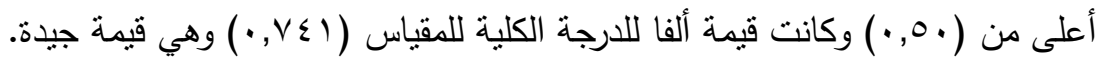
ثبات وصدق مقياس المتغيرات الاجتماعية: قد قام الباحثون بإعداد مقياس المتغيرات الاجتماعية للطالبات بالاستعانة ببعض الدراسات السابقة ومنها دراسة هدى احمد عبداله

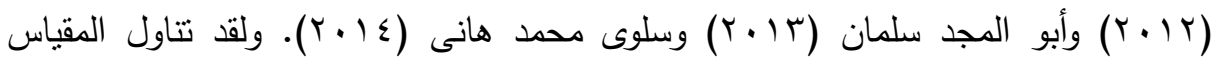
متغيرات البيئة الاجنماعية المدرسية ثلاث أبعاد وهم (العلاقة مع زميلات المدرسة) و (العلاقة 
مع المعلمين) و (العلاقة دع الادارة المدرسية). ولقد تتاول المقياس متغيرات البيئة الاجتماعية فى محيط الأسرة ثلاث أبعاد وهم (العلاقة مع الأب) و (العلاقة مع الأم) و (العلاقة مع الأخوة

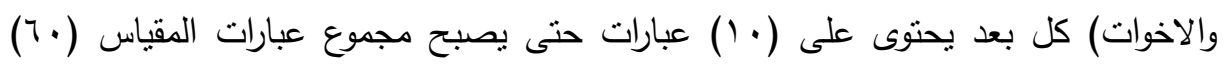

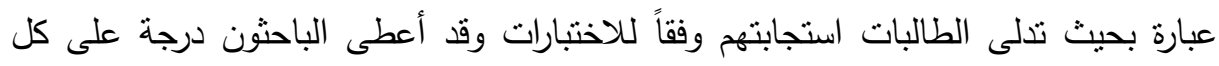

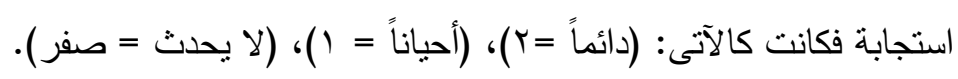

بالنسبة لحساب الثبات: للتحقق من ثبات المقياس استخدم الباحث معادلة ألفا كرونباخ ويوضح الجدول التالي معاملات الثبات الناتجة باستخدام هذه

المعادلة.

يتضح من الجدول أن قيم معاملات الثبات لأبعاد البيئة الاجتماعية الددرسية قيم مقبولة

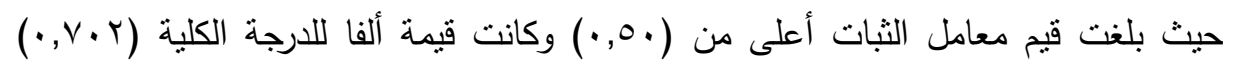

$$
\text { وهي قيمة جيدة. }
$$

\begin{tabular}{|c|c|c|c|c|c|c|}
\hline \multicolumn{2}{|c|}{ إجمالى العينة } & \multicolumn{2}{|c|}{ المدارس الخاصة } & \multicolumn{2}{|c|}{ المدارس الحكومية } & \multirow{2}{*}{ الصف الدراسي } \\
\hline النسبة & العدد & النسبة & العدد & النسبة & العدد & \\
\hline$r Y, \varepsilon$ & $7 V$ & V & V & r. & 7. & الصف الأول \\
\hline$r \varepsilon, r$ & $1 \cdot r$ & rV & rV & rᄉ & VT & الصف الثاني \\
\hline$\varepsilon r, r$ & IT. & 77 & 77 & Tr & $7 \varepsilon$ & الصف الثالث: \\
\hline $1 \ldots$ & r.. & $1 \ldots$ & $1 \cdots$ & $1 \cdots$ & $r .$. & الإجمالي \\
\hline
\end{tabular}

جدول (1) : الأعداد والنسب لعينة الدراسة تبعاً لمتغير الصف الدراسي

من الجدول السابق لوصف عينة الدراسة تبعاً لمتغير الصف الدراسي كانت عينة الدراسة

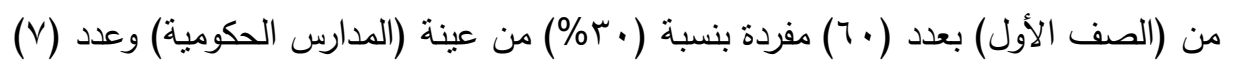

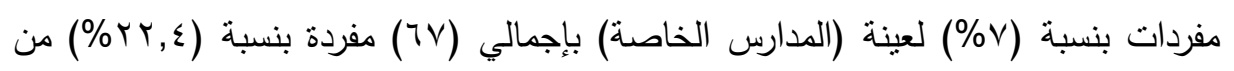

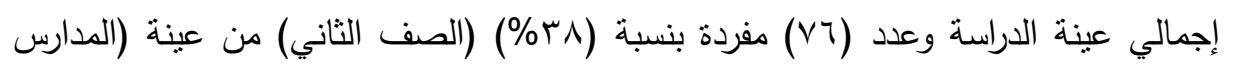

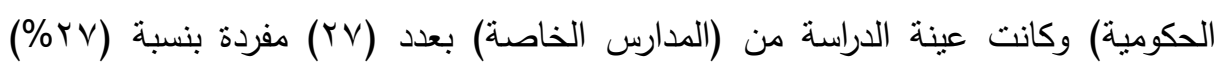

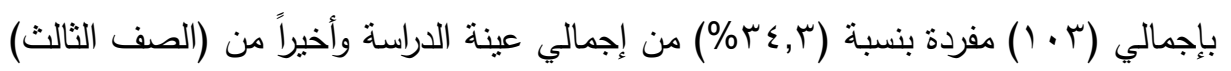

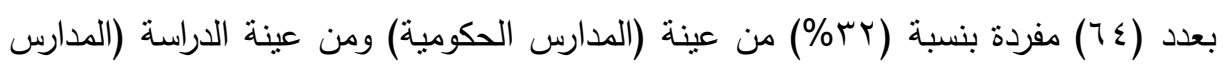

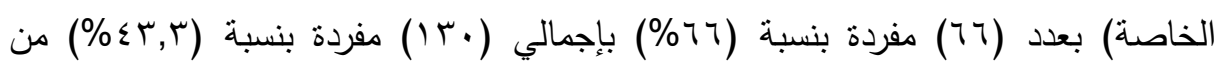
إجمالي عينة الدراسة. 
جدول(ץ): البيانات الوصفية (الوسط الحسابي والإنحراف المعياري) للبيانات الرقمية لعينة الدراسة

\begin{tabular}{|c|c|c|c|c|c|c|c|}
\hline عدد غرف & ترتيب الطالبة & الاناث & الذكور & عدد افراد & السن & \multicolumn{2}{|l|}{ المتغيرات } \\
\hline$r, 1$ & $r, 7 V$ & $r, \Lambda r$ & $1, \mathrm{VV}$ & $\varepsilon, \Sigma 1$ & 17,01 & الوسط الحسابي & المدارس \\
\hline$\cdot, \wedge 9$ & $1, r v$ & $1, \varepsilon 1$ & $1, \cdot v$ & $r, 17$ & $\cdot, 91$ & |الإنحراف المعياري & الحكومية \\
\hline$r, v q$ & $1,9 \vee$ & Y,YT & 1, ro & $r, 00$ & $I V, Y T$ & الوسط الحسابي & المدارس \\
\hline • & $\cdot, 90$ & 1,11 & $1, \cdot 1$ & $1, \Lambda \Gamma$ & 1,9 . & الإنحراف المعياري & الخاصة \\
\hline$r, 99$ & $r, \varepsilon r$ & $Y, 7 \varepsilon$ & זיד & $\varepsilon, 1 Y$ & 17,87 & الوسط الحسابي & \\
\hline$\cdot, \wedge \Lambda$ & $1, r q$ & $1, \Gamma \varepsilon$ & $1, .9$ & $r, 1$. & $1, \varepsilon$. & الإنحراف المعياري & \\
\hline
\end{tabular}

الجدول السابق يوضح البيانات الوصفية (الوسط الحسابي والإنحراف المعياري) للبيانات

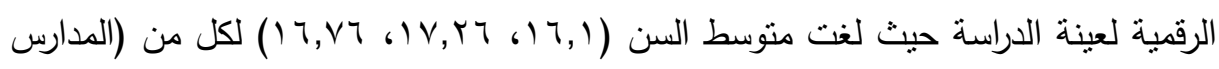

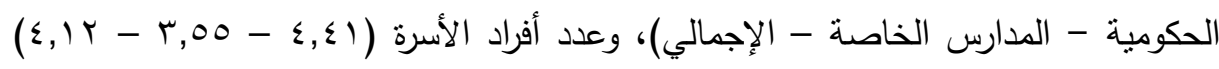

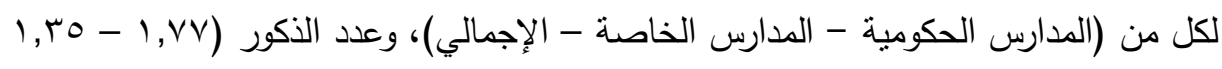
- rا7, 1) لكل من (المدارس الحكومية - المدارس الخاصة - الإجمالي)، وعدد الإناث

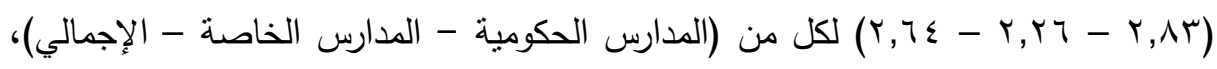

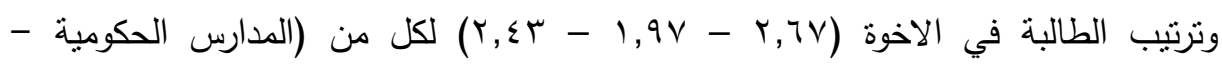

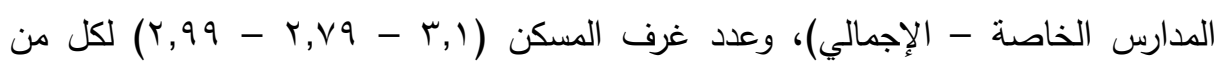
(المدارس الحكومية - المدارس الخاصة - الإجمالي).

\section{Andist}

الفرض الأول: توجد علاقة ارتباطية ذات دلالة احصائياً بين الضغوط النفسية والمتغيرات

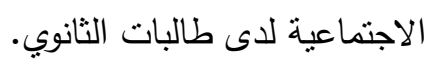


جلول(ب): العلاقة بين الضغوط النفسية والمتغيرات الاجتماعية لدى عينة من طالبات الثانوي

\begin{tabular}{|c|c|c|c|c|c|c|c|c|}
\hline الاجتغيراتي & العلاخة مع & لعلاقة مع الام & العلابة مع & اللعلاقة مع اللدارة & المعلمين مع & | زلعلاقة مع | لمدربة & \multicolumn{2}{|c|}{ المتغيرات } \\
\hline "*, or & "r, "r, & $" \cdot, 7 ו 1$ & " " & $" ., 10 \mathrm{~V}$ & $" \cdot, r \leq 1$ & $" *, 100$ & الارتباط & ضغوط \\
\hline$\cdot, \ldots 1$ & $\cdot, \ldots l$ & $\cdot, \cdots)$ & $\cdot,, \cdots$ & $\cdot, \ldots 7$ & $\cdot, \ldots l$ & $\cdots, \cdots v$ & الدعنولة & الاخرين مع \\
\hline$" *$, ov. & * $\cdot, r q r$ & " "., & "* ". & $"$ ", ror & " & $\because, r \neg \leqslant$ & مالارتاط & الضغوط \\
\hline$\cdot, \ldots 1$ & $\cdot, \cdot$, & $\cdot, \cdots)$ & $\cdot, \cdots$ & $\cdot, \cdots)$ & $\cdot, \cdots)$ & $\cdot, \ldots l$ & الدعنولة & الاقتصادية \\
\hline$* \cdot, r q 1$ & $\cdot, \cdot r r-$ & & "*., ". & $", r, r_{01}$ & $" *, r \leq \varepsilon$ & זسו,." & معامل & الضغوط \\
\hline$\cdot, \ldots 1$ & $\cdot, \mathrm{V}$ & T, &,,$\ldots l$ & $\cdot, \ldots l$ & $\cdot, \ldots l$ & $\cdot, \cdot r$ & الدعنولة & الدراسية \\
\hline$* *, r \leqslant r$ & $* ., 110$ & " ".,01 & $" *, Y T V$ & ., & & •, . 97 & معامل الارتباط & الضغوط. \\
\hline$\cdot, \ldots)$ & $\cdot, \cdot$, & $\cdot, \cdot$, & $\cdot, \cdots)$ & $\cdot, 0 . r$ & $\cdot, \cdot r$ & $\cdot, 1$ & المعنولة & يصورة الجسم \\
\hline$" *$, rov & $" *, r \vee T$ & $" *, T \leqslant r$ & " " & מגז, " & $* " \cdot, \varepsilon \cdot r$ & $* \theta, r \leqslant r$ & معامل & مقياس \\
\hline$\cdot, \ldots 1$ & $\cdot, \ldots l$ & $\cdot, \ldots)$ & $\cdot, \ldots$ & $\cdot, \cdots)$ & $\cdot, \ldots l$ & $\cdot, \ldots l$ & الدعنولة & الضفسية \\
\hline
\end{tabular}

يتبين من الجدول السابق وجود علاقة ارتباطية ذات دلالة احصائياً بين أبعاد الضغوط النفسية والمتغيرات الاجتماعية لدى العينة الكلية من طالبات الثانوي عند مستوى معنوية

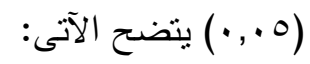

• لقد اتضح وجود علاق إرتباطية ذات دلاله احصائية بين بعد العلاقة مع زميلات المدرسة

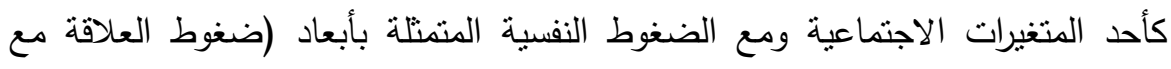

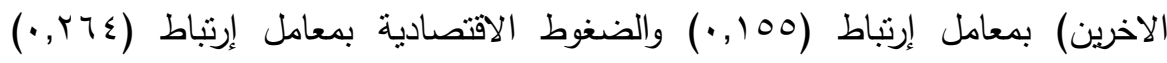

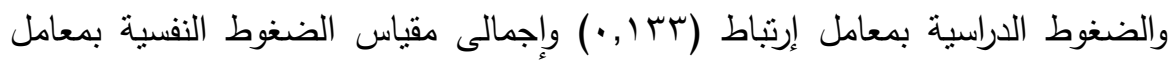

$$
\text { إرتباط ( ) }
$$


كما تنين أنه لاتوجد علاقة إرتباطية بين بعد الضغوط بشكل الجسم وبعد العلاقة مع

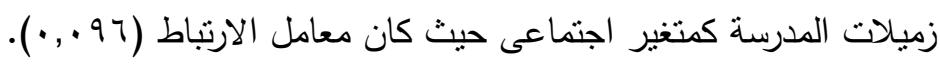

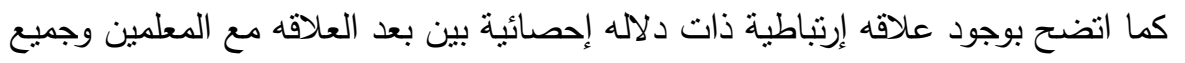

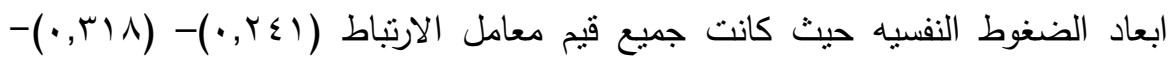

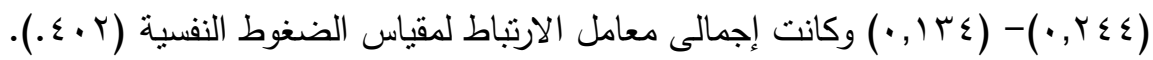
• أما عن بعد العلاقه مع ادارة المدرسه من بين المتغيرات الاجتماعيه وجود علاقه إرتباطيه

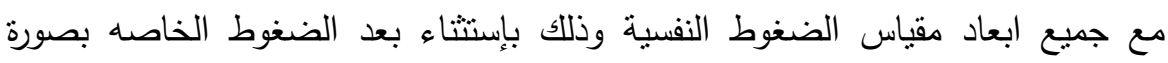

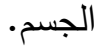
• أما عن بعد العلاقه مع الاب فقد اتضح وجود علاقه إرتباطية ذات دلاله إحصائيه مع جميع ابعاد مقياس الضغوط النفسيه. • ولقد وجد علاقه إرتباطية ذات دلاله احصائية بين العلاقه مع الام وجميع ابعاد مقياس الضغوط النفسيه بإستثناء بعد الضغوط الدراسية.

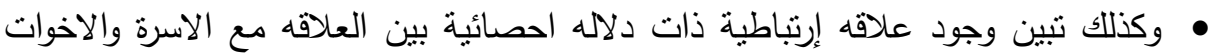
وبين جميع ابعاد مقياس الضغوط النفسية وذللك بإسستثناء بعد الضغوط الدراسيه. • وقد تبين أن اجمالى المتغيرات الاجتماعية أوضح وجود علاقه إرتباطيه ذات دلاله احصائيه مع جميع ابعاد مقياس الضغوط النفسية. • ومن هنا يتبين جدول رقم (r) وجود علاقه إرتباطية ذات دلاله إحصائية بين ابعاد الضغوط النفسية والمتغيرات الاجتماعية لاى عينه الكلية من طالبات الثانوى عند مستوى إنى معنوى (0. .) وعليه يتحقق الفرض الاول فى متغير العينة الكلية.

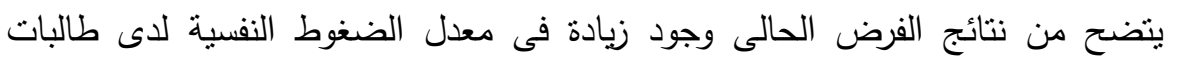
الثانوى يتأثرون بالضغط النفسى وتختلف شدة الضغط من طالبة إلى أخرى ويرجع تأثنر الضغط النفسى على رد فعل على آنفعالتهم حسب شخصية كل منهما وظروفهم ومكوناتهم الثخصية والنفسية وذلك يرجع إلى عدة عوامل سن المراهقة لأن هذا السن أكثر عرضية

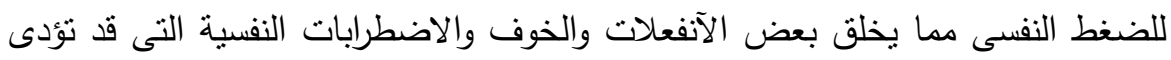

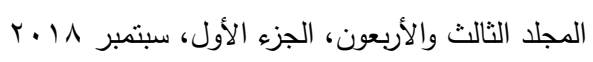


إلى تأثثرات انفعالية وعدم القدرة على تخزين المعلومات واسترجعها وتدهور قوة النتظيم والتخطيط ويصبح العقل غير قادر على التقييم بدقة واضطراب أنماط التفكير ومن نتائج

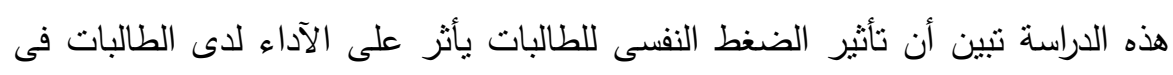

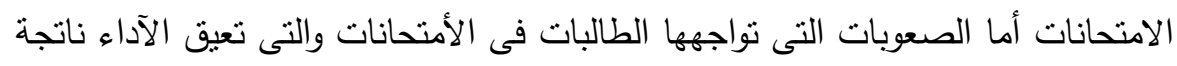

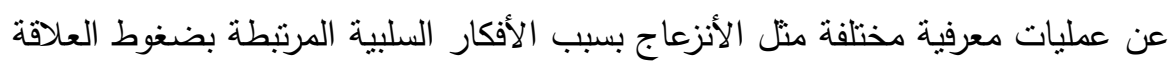

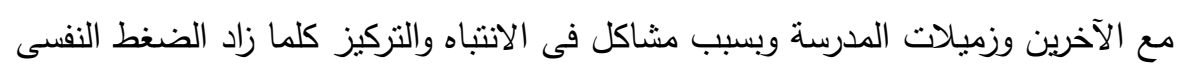

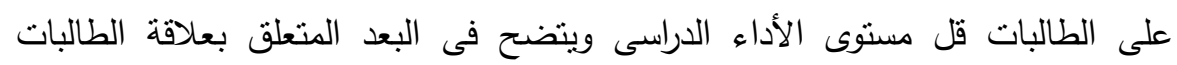
بالمعلمين يمتلون ضغوط عليهم وذلك بأعطائهم كم كبير من الدروس اليومية بدون شرح كافى مع عدم نتجيع الطالبات على متابعة طريق النجاح والواجبات المرنبطة بالدراسة

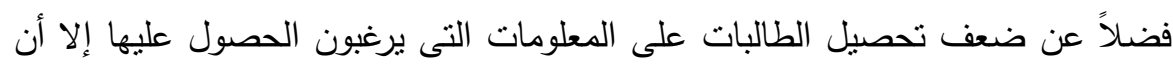

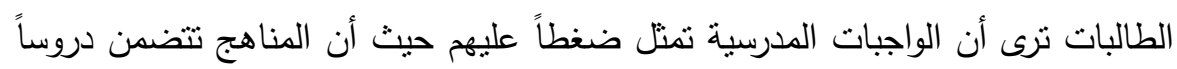
يصعب على الطالبات فهمها وقد تبين أن القيود التى تقرضها الأسرة على الطالبات

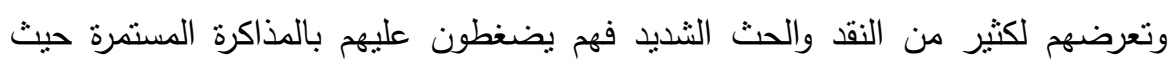

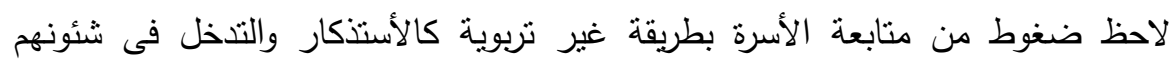

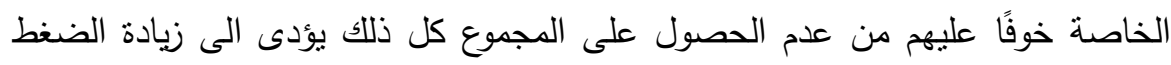

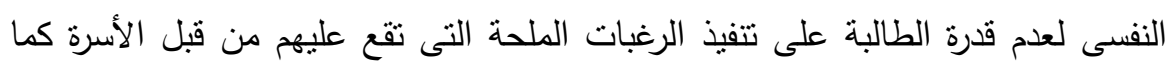
تبين أيضاً من خلال علاقة الطالبات بزميلات المدرسة كإحدى المتغيرات الأجتماعية

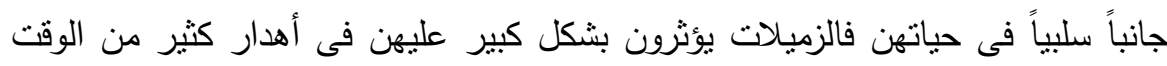

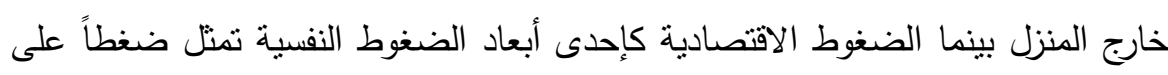

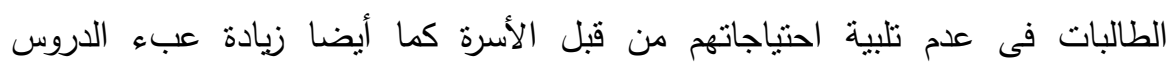
الخصوصية وذلك لعدم شرح المعلمين الوافر لهم داخل الفصل الدراسى وبالنسبة لبعد العلاقة مع الآخرين وخاصة أن المحطين والمقربين منهم ينتظرون النتيجة المثالية

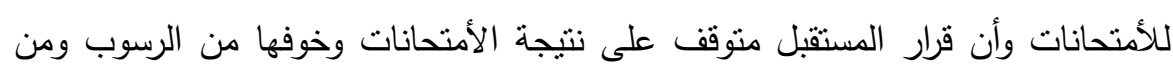

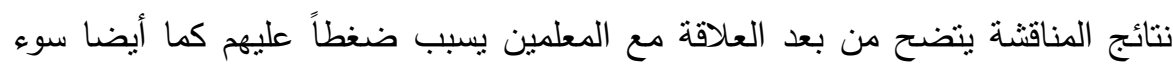

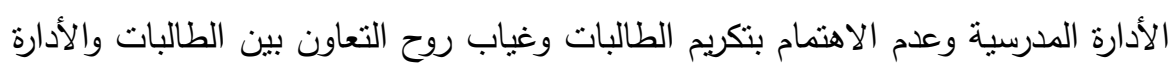


المدرسية وعدم ضبط العملية التعليمية ويتضح من ذلك أن الطريقة أو الأسلوب المتمعد فى تقدمة للارس يؤثز على تحصيل الطالبات كلما إعتمد المدرس على طريقة مرنة تتماشى دع قدرات الطالبات واحتياجاتهم كلما وجد البديل ومن خلال الواجبات والمراجعة إستدراك ما فهمته من معلومات.

أكدت الدراسة الحالية على وجود مستوى مرتفع من الضغوط النفسية التى تقع على معلى الطالبات من حيث (العلاقة مع زميلات - العلاقة مع المعلمين - العلاقة مع الإدارة

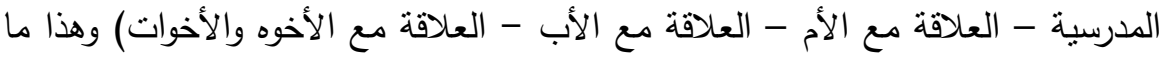
أكدتة نتيجة دراسة هداية بنت صالح (10 ب ب) وجود مستوى مرتفع من الضغوط النفسية وآثرها على طالبات المرحلة الثانوى وقد تتاولت دراسة (Pocola \& ILugbo, 2010) ودراسة (Kardum, I. \& Karpic, 2003) بعض الخصائص النفسية والسمات الثخصية للطالبات بصفة عامة والمرحلة الثانوية بصفة خاصة كما أكدت على ذلك دراسة عمر مصلحى (10 ب (10) على وجود علاقة آرتباطية بين الضغوط النفسية وبعض المتغيرات الأجتماعية من حيث العلاقة مع الأسرة وأدارة المدرسة وزميلات المدرسة وقدا بـد

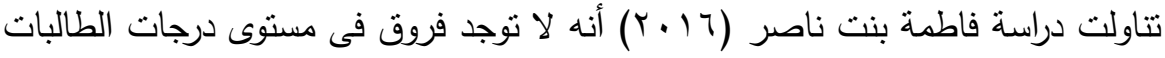

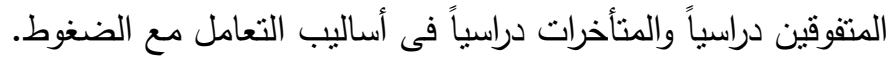
• وتتطبق نتيجة الفرض الحالى مع بعض المداخل النظرية التى تتاولت نأثير الضغوط النفسية على حباة الفرد بشكل سلبى وتفرض على الفرد نأثثرات سلبية قد تكون أجتماعية أو نفسية أوجسية الى جانب (النظرية البيولوجية) التى ركزت على كون المراهقة لسيت منفصلة عن الطفولة والرشد وتعتبر مرحلة المراهقة مرحلة عواصف وضغوط تولد فيها

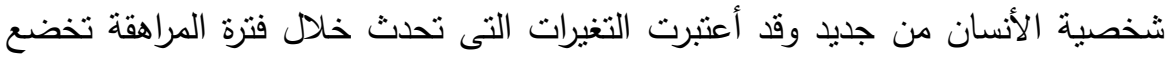
كليًا سلسلة من العوامل الفسيولوجية وهذا ما يتضح لنا أن الطالبات فى سن المراهقة يبدو عليهم الآنفعال سريعًا وهذا ما يؤثر على علاقتهم بالآخرين من معلمين وزملاء المدرسة والآسرة ومن تلك النظريات أيضًا التى نؤكد على صحة هذا الفرض (نظرية هانز سيلى) والذى يتضح أن ما يعتبر ضاغطًا للفرد لا يعتبر كذلك لفرد أخر ويتوقف على سمات هده 
الثخصية للفرد وخبراته الذاتية وقدرتة على الضغوط كما بتوقف على عدة عوامل ذات

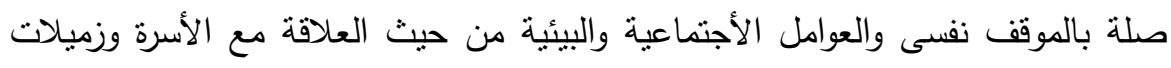
المدرسة والمعلمين وهذا ما يتفق معه هذا الفرض.

الفرض الثاني: توجد علاقة ارتباطية ذات دلالة إحصائياً بين الضغوط النفسية والمتغيرات البيئية لدى طالبات الثانوي. جدول (ء) ): العلاقة بين الضغوط النفسية والمتغيرات البيئية لاى عينة من طالبات الثانوي

\begin{tabular}{|c|c|c|c|c|c|}
\hline |جمالي المتغيرات & بيئة منطقة & |بيئة الاسرة| & بيئة المدرسة & \multicolumn{2}{|c|}{ المتغيرات } \\
\hline$* *,, \Sigma \vee$ & **, r . & $* *, \leq \leq \leq 0$ & $* *$, ror & معامل الارتباط & \multirow{2}{*}{ ضنغوط العلاقات مع } \\
\hline$\cdot, \cdots 1$ & $\cdot, \cdots 1$ & $\cdot, \cdots 1$ & $\cdot, \cdots 1$ & الدلالة المعنوية & \\
\hline$* *, 717$ & $* *,, \leq 07$ & $* *$, orr & $* *, \leq\rceil 1$ & معامل الارتباط & \multirow{2}{*}{ الضغوط الاقتصادية } \\
\hline$\cdot, \cdots 1$ & $\cdot, \cdots 1$ & $\cdot, \cdots 1$ & $\cdot, \cdots 1$ & الدلالة المعنوية & \\
\hline$* *, 191$ & $\cdot, \cdot 19$ & **, * & $*, 1 \leq 0$ & معامل الارتباط & \multirow{2}{*}{ الضغوط الدراسية } \\
\hline$\cdot, \ldots 1$ & •, Irr & $\cdot, \cdots 1$ & $\cdot, \cdot 1 r$ & الدلالة المعنوية & \\
\hline$* *, 01 Y$ & $* *, r 97$ & $* *, \ldots \vee q$ & $* *, \mu) \varepsilon$ & معامل الارتباط & \multirow{2}{*}{ الضغوط الخاصة } \\
\hline$\cdot, \ldots 1$ & $\cdot, \cdots 1$ & $\cdot, \cdots 1$ & $\cdot, \cdots 1$ & الدلالة المعنوية & \\
\hline$* *, \neg \wedge 1$ & $* *, \Sigma \vee \mu$ & $* *, 7 \leq 7$ & $* *, \leqslant \vee q$ & معامل الارتباط & \multirow{2}{*}{ الضمالي مقياس النفية } \\
\hline$\cdot, \cdots 1$ & $\cdot, \cdots 1$ & $\cdot, \cdots 1$ & $\cdot, \cdots 1$ & الدلالة المعنوية & \\
\hline
\end{tabular}

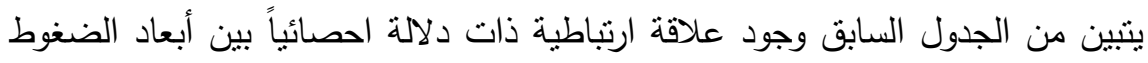
النفسية والمتغيرات البيئية لدى العينة الكلية من طالبات الثانوي عند مستوى معنوية (0. . •).

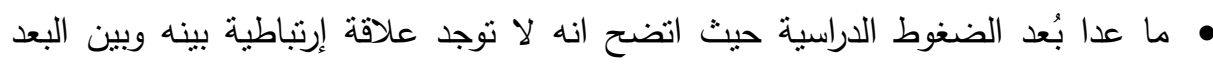
البيئى الممثل فى بيئة منطقة السكن. وجود علاقة ارتباطية ذات دلالة احصائياً بين أبعاد

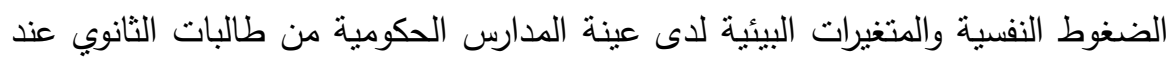

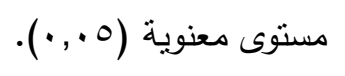

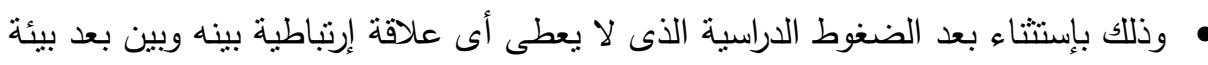

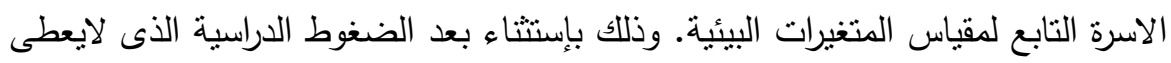
أى علاقة إرتباطية بينه وبين بعد بيئة منطقة السكن التابع لمقياس المغيرات البيئية. 
هيتضح مما سبق صحة الفرض الثاني: توجد علاقة ارتباطية ذات دلالة احصائياً بين الضغوط النفسية والمتغيرات البيئية لدى طالبات الثانوي.

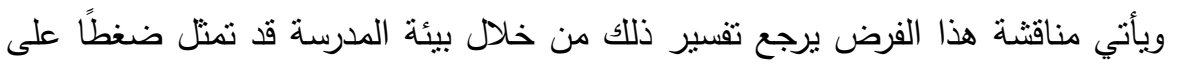

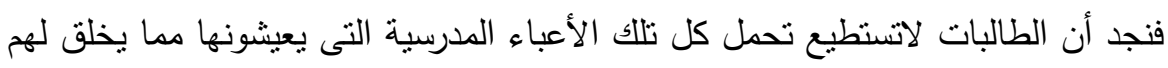

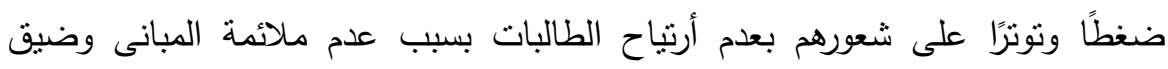
الفصول كما أيضًا وجود تهوية غبر جيدة داخل الفصل الدراسى أو لخلو الحياة الددرسية

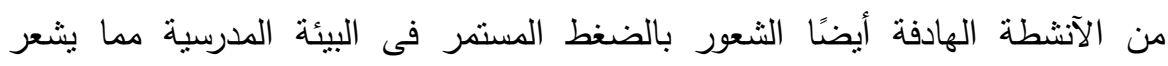

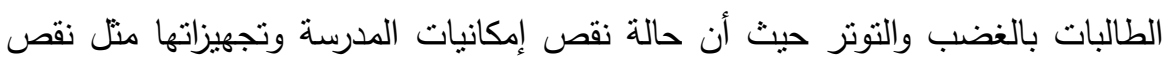
الوسائل والمعامل وعدم وجود غرف مخصصة لها ونقص وجود ملاعب وساحات لممارسة الأنشطة وضعف الإضاءة المناسبة وسوء التهوية وغير ذلك من الأمور المتعلقة بالطالبات فإن هذا كله يؤثز سلبًا عليهم بشكل خاص وعلى الددرسة بشكل عام وتظهر هذه الآثار

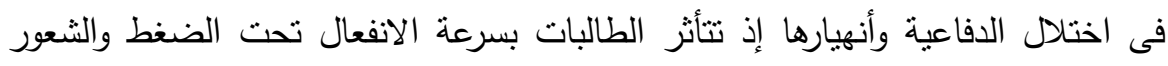
بالقلق وعدم الراحة مما قد يصاحبة الخوف الثديد وفقدان الثقة بالنفس وفى الآخرين. وأيضًا نؤدى الضغوط وعنى إلى نقص الإنتباه وقلة التركيز وأضطراب التفكير حيث جمود التفكير وأنخفاض الآداء الدراسى حيث تتفق هذه النتيجة مع دراسة احسان حميدان

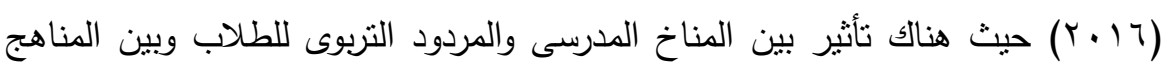
التعليمية أما من حيث تأثير المتغيرات البيئية الخاص ببعد بين بيئة الأسرة وجود نتيجة عكسية

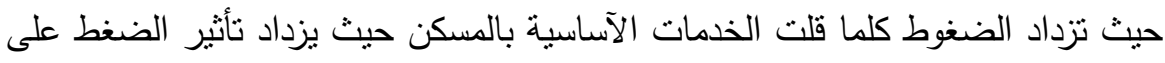
الطالبات المتمثل فى عدم نوافر مناخ للمذاكرة وعدم وجود خاصة بالطالبة وكثرة الضوضاء وذلك يؤثز على الحالة الصحية والنفسية للطالبات وهذا يتفق مع دراسة علاء

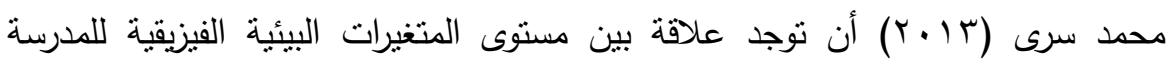

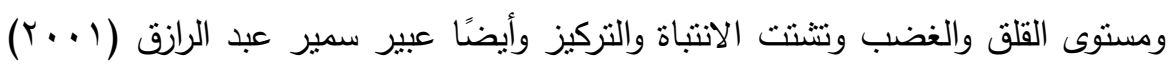

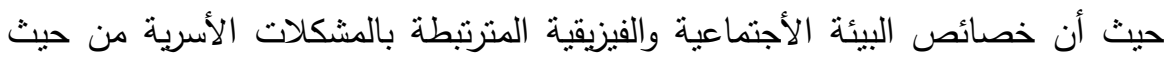
الجانب الاقتصادى والاجتماعى والخدمات الأساسية بالمسكن وحالة المسكن والحى لهم

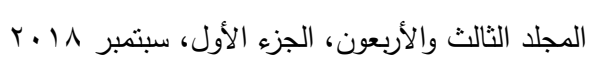


بالغ الأثر فى المردود النفسى الذى يقع على الطالبات حيث جاء فى تفسير ذلك (النظرية

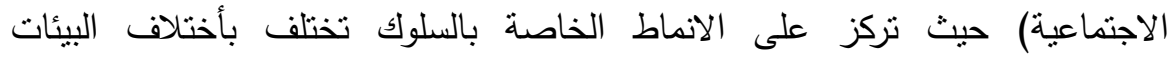

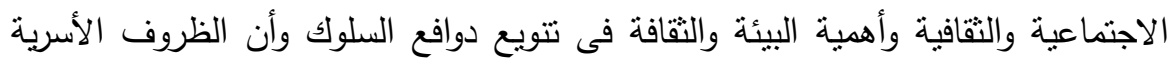

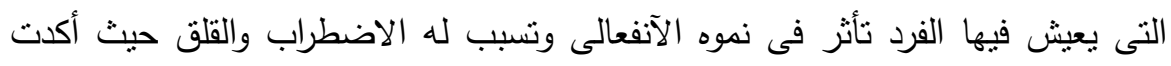

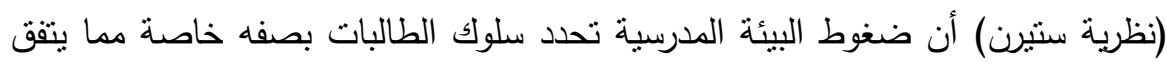
مع نتيجة هذا الفرض من حيث وجود علاقة بين الضغوط النفسية والمتغيرات البيئية سواء بيئة المدرسة أو الأسرة وبيئة منطقة السكن. الفرض الثالث: توجد فروق ذات دلالة احصائية بين متوسطات درجات طالبات الثانوي لمقياس الضغوط النفسية تبعاً لمتغير الصف الدراسي. جدول(ه): اختبار ف ANOVA لتوضيح الفروق الإحصائية بين طالبات الثانوي لـقياس

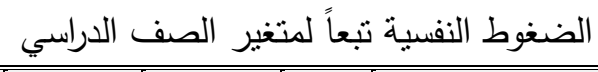

\begin{tabular}{|c|c|c|c|c|c|c|c|}
\hline مستوى الدلالة عند (ه م. . ) & المعنوية المة & قيمة ف & الإنحرياري & الحسبابي الوسط & العدد العد & \multicolumn{2}{|c|}{ المتغيرات } \\
\hline \multirow{4}{*}{ دالة ل } & \multirow{4}{*}{$\cdot, \cdot 1$} & \multirow{4}{*}{$\varepsilon, r \vee T$} & $r, q r$ & YI,9V & $7 V$ & الصف الأول & \multirow{4}{*}{ ندغ الآخرين العلاقات } \\
\hline & & & $r, Y \tau$ & rT, TO & $1 . r$ & الصف الثانى & \\
\hline & & & $r, \wedge 1$ & $r r, 1 \wedge$ & $1 \pi$. & الصف الثالث & \\
\hline & & & $r, v$. & $r r, \cdot V$ & r.. & الإجمالي & \\
\hline \multirow{4}{*}{ غير دالة } & \multirow{4}{*}{$\cdot, r$} & \multirow{4}{*}{$1, Y Y T$} & $r, 0 \leqslant$ & $r Y, 9 q$ & $7 V$ & الصف الأول & \multirow{4}{*}{ الاقتصنادية } \\
\hline & & & $r, 71$ & $r r, \lambda l$ & $1 . r$ & الصف الثانى & \\
\hline & & & $r, r q$ & $r T, 70$ & $1 \pi$. & الصف الثالث & \\
\hline & & & $r, \leq \tau$ & rT,00 & $r \ldots$ & الإجمالي & \\
\hline \multirow{4}{*}{ دالة ل } & \multirow{4}{*}{$\cdot, \cdots$} & \multirow{4}{*}{$1 \cdot, 974$} & $\varepsilon, Y\}$ & $r, \varepsilon T$ & $7 V$ & الصف الأول & \multirow{4}{*}{ ضغوط الدراسية } \\
\hline & & & $\varepsilon, \cdot r$ & $M Y, \wedge \varepsilon$ & $1 \cdot r$ & الصف الثانى & \\
\hline & & & $\varepsilon, \wedge \vee$ & 10,11 & $1 \pi$. & الصف الثالث & \\
\hline & & & $\varepsilon, 71$ & $r r, V \varepsilon$ & $r .$. & الإجمالي & \\
\hline \multirow{4}{*}{ دالة } & \multirow{4}{*}{$\cdot, \cdots r$} & \multirow{4}{*}{ אחז,ד } & $\varepsilon, T r$ & $r \varepsilon, 1 Y$ & $7 V$ & الصف الأول & \multirow{4}{*}{ بصغورة الخاصة } \\
\hline & & & $\varepsilon, 9 V$ & Yo, 1 & $1 \cdot r$ & الصف الثانى & \\
\hline & & & $r, q 7$ & $r r, 90$ & $1 \pi$. & الصف الثالث & \\
\hline & & & $\varepsilon, \varepsilon 9$ & $r r, 9 r$ & 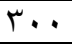 & الإجمالي & \\
\hline \multirow{4}{*}{ دالة } & \multirow{4}{*}{$\cdot, .0$} & \multirow{4}{*}{$r, . q$} & 9,10 & $1,1,0 \leqslant$ & $7 V$ & الصف الأولَ & \multirow{4}{*}{ لضغالى مقياس النفسية } \\
\hline & & & $1 \cdot, \wedge$. & $1 \cdot 0, r$. & $1 . r$ & الصف الثانى & \\
\hline & & & $1 \cdot, 11$ & $1 \cdot \varepsilon, \wedge \wedge$ & $1 \%$. & الصف الثالث & \\
\hline & & & $1 \cdot, \varepsilon$. & $1 \cdot \varepsilon, Y \wedge$ & r... & الإجمالى & \\
\hline
\end{tabular}


من الجدول السابق للفروق الإحصائية بين متوسطات درجات طالبات الثانوي لكقياس الضغوط النفسية تبعاً لمتغير الصف الدراسي يتبين الآتي:

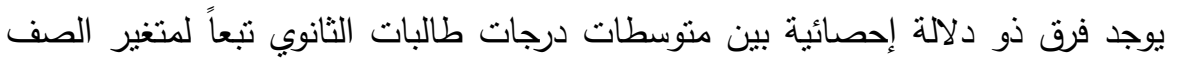

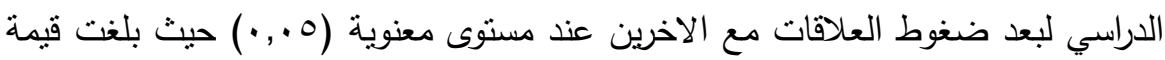

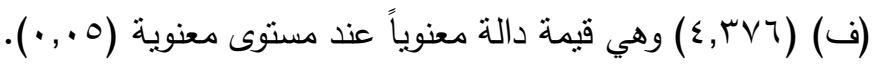

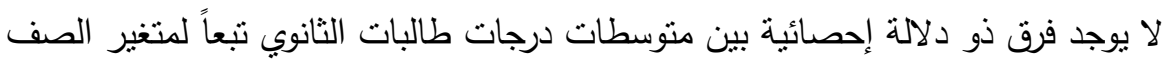

$$
\text { الدراسي لبعد الضغوط الاقتصادية عند مستوى معنوية (0. . • ). }
$$

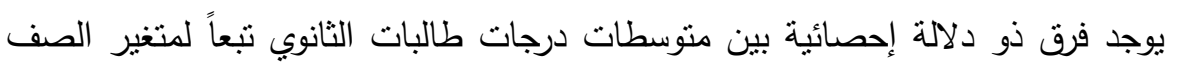

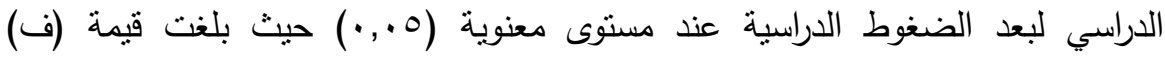

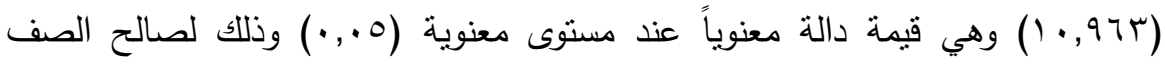

هوجد فرق ذو دلالة إحصائية بين متوسطات درجات طالبات الثانوي نبعاً لمتغير الصف

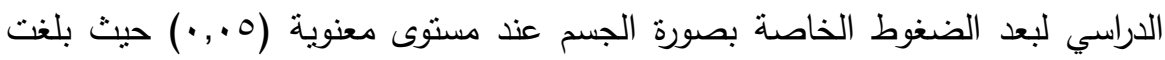
قيمة (ف) (Tr,Tr,) وهي قيمة دالة معنوياً عند مستوى معنوية (0., •). وذلك لصالح الصف الثانى.

يوجد فرق ذو دلالة إحصائية بين منوسطات درجات طالبات الثانوي تبعاً لمتغير الصف الدراسي لاجمالي مقياس الضغوط النفسية عند مستوى معنوية (0., •) حيث بلغت قيمة

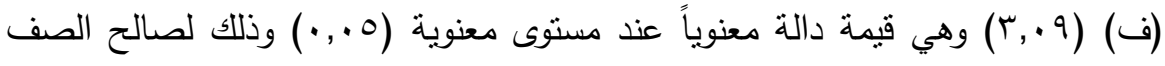
الثانى. مما سبق ثبت صحة الفرض الساد: نوجد فروق ذات دلالة احصائية بين منوسطات

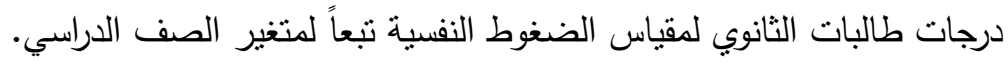

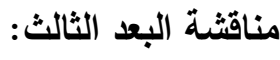
• يتضح ذللك من خلال البعد الخاص بالضغوط الدراسية بالمرحلة الدراسية النهائية وهى

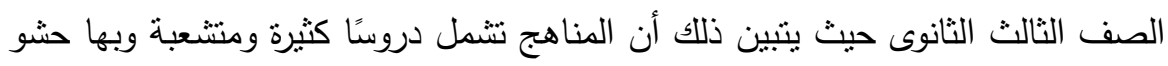


وتكرار حيث أن الإطاله وكثرة الموضوعات لها أثز سلبى على الطالبات فى مذاكرتها فيزداد عليهم القلق وضعف التركيز حيث يشعرون بالعجز فى تحقيق أهدافهم وطموحاتهم الإنى الدراسية ويؤدى الى إعاقة تقدمه الدراسى لذلك تعانى الطالبات أثثاء فترة الامتحانات بالضغط النفسى لخوفهم من مستوى إجابتهم وحصولهم على درجات لم يرضون إعلى عنها وبالتالى يصعب عليهم أعادة نرتيب المعلومات التى يدرسونها حسب أهميتها وتضطر الهبر

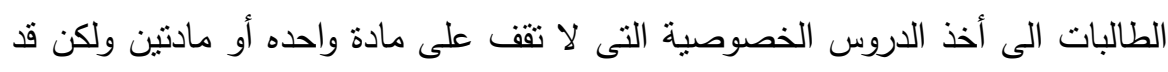

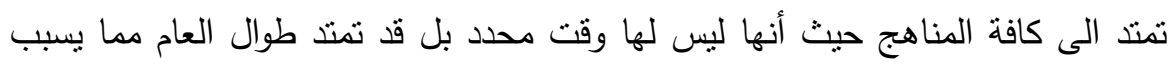

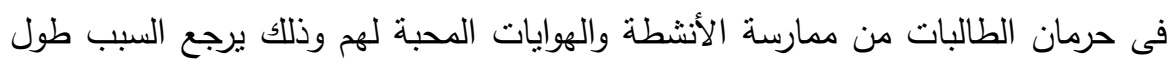

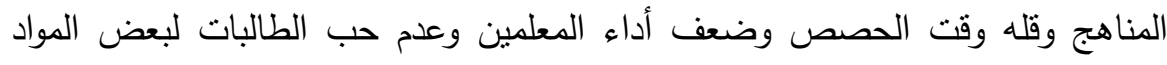
التى يدرسونها وهذا يؤدى الى حرمان بعض الطالبات من احتياجاتهم الثخصية مما يؤثر عليهم ويمثل ضغطاً دراسيًا لهم.

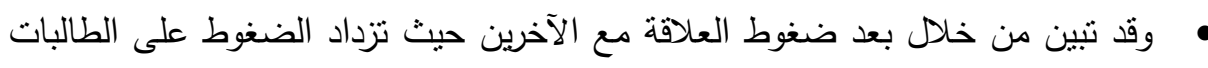

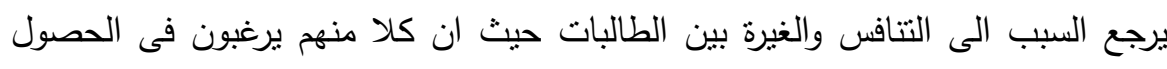

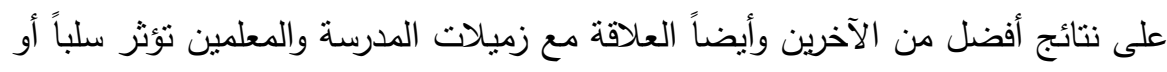

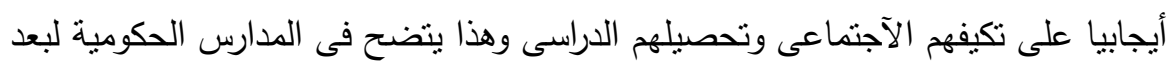

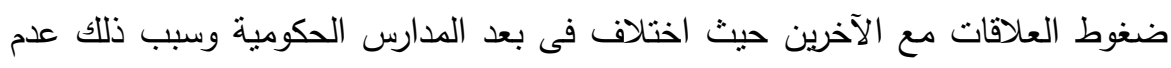

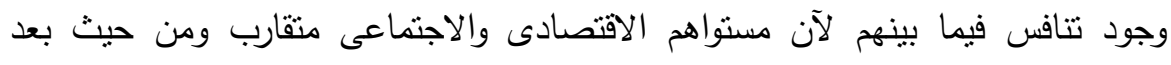

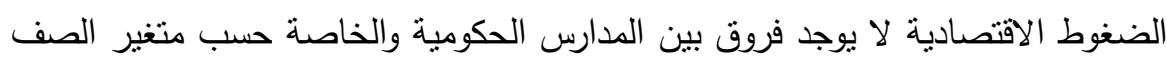
الدراسى لآن التكاليف الدراسية تعتبر واحده سواء فى جميع المراحل الثلاثه حيث توفر لإني

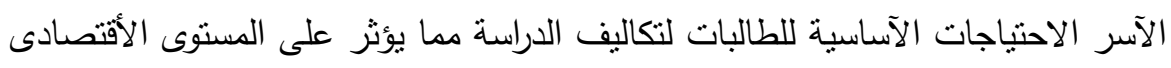

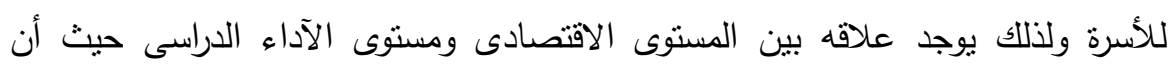
الصعوبات المادية التى تواجه الطالبات نتيجة سوء الوضع الأفتصادى ونقص الأمكانيات

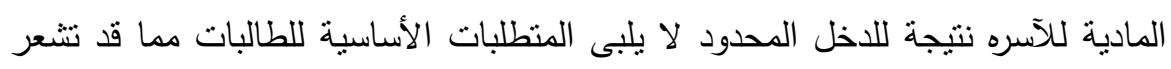

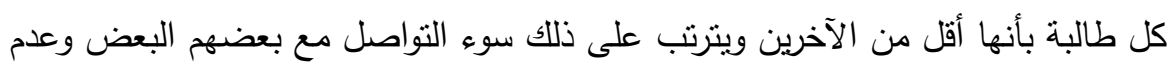
القدرة على التوافق مع المحطين بهم. بالها 
حيث أكدت الدراسة الحالية على تأثثر الضغوط النفسية وذلك من خلال أبعاد ضغوط العلاقات مع الآخرين الضغوط الأقتصادية الضغوط الخاصة بصورة الجسم لدى الطالبات

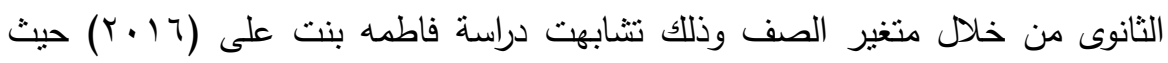

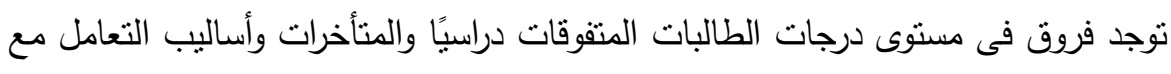

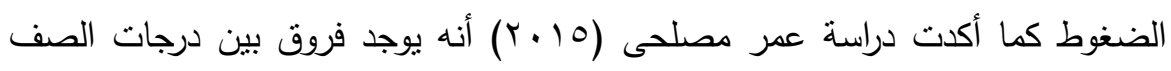

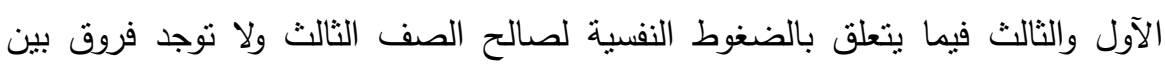
متوسطات عينة الدراسة فى أساليب الضغوط النفسية المدرسية والضغوط الضغولة الآسرية وأساليب

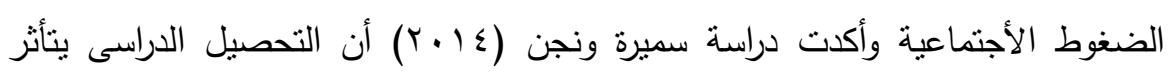
بالمتغيرات الوسط الاجتماعى والتأثيرات الصفية ووأكدت دراسة (Peterson, 2009) أن ونئن مجموعة المصادر التى يعانى منها الطلاب تتمنل فى ضغوط وأكاديمية وضغوط الرفات الرفاق وقد دعمت النتيجة الحالية النظريات التى فسرت الضغوط النفسية والتى منها (نظرية ستيرن) فى افتراضه أن الضغوط المدرسية تحدد سلوك الطالبات بصفة خاصة إما تنير أو تعوق جهدهم التى تستهدف إثباع حاجاتهم وأهدافهم وذللك ماأكدت عليه أيضا (نظرية موراى هانرى) بأن الضغط صفة لموضوع بيئى تيسر أو تعوق جهر الفرد للوصول إلى تهن

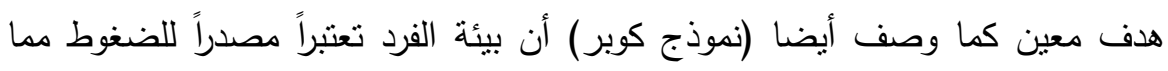

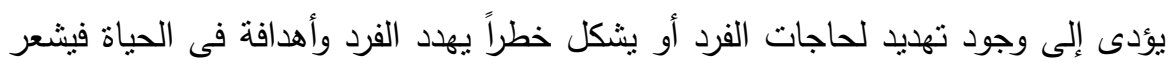
بحالة من الضغط. 


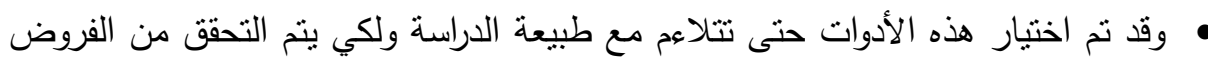

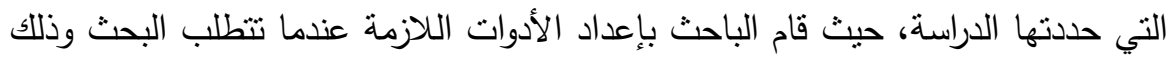
بعد التأكد من صحة ثباتها وصدقها، كما نم حساب ثنات وصدق المقاييس الني أعدها الباحث.

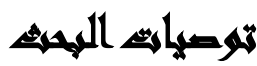

1- العمل على تقليل من الضغوط النفسية الدراسية التى يعانى منها الطالبات من حيث نطوير المناهج وتوفير إمكانيات مادية مناسبة. r-مراعاة الفروق الفردية بين الطلبة فى الفصل الدراسى مع ضرورة إدارة الصف بشكل جيد وفهم حاجات ورغبات الطالبات. r-أن تعمل المدرسة على الموازنة بين عدد المعلمين ومساحة المدرسة وعدد الأقسام بها وعدد الطالبات حتى لايحدث ضغط يؤثر سير العملية التعليمية وفق أهدافها.

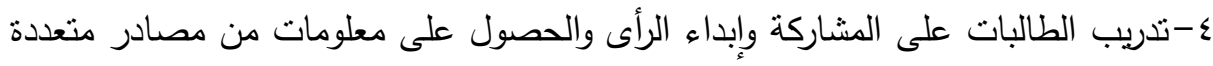
بما يفجر طاقتهم وينمى لديهم الثقة بالذات والمواجهة الإيجابية للضغوط وفهم العالم من حولهم. ه-توجيه نظر العاملين فى المجال التربوى بضرورة الاهتمام بالضغوط التى يتعرض لها الطالب فى المرحلة الثانوية عند التخطيط وإعداد البرامج التربوية المختلفة.

\section{المرالئ2}

على عسكر ( . . † ץ): ضغوط الحياة وأساليب مواجهنها، دار الكتاب الحديث، الطبعة الثانية. عباس فاضل خلف( • • ب): العوامل المؤثرة على المستوى الدراسى لطلبة المدارس الثانوى، مجلة الدراسات التربوية.

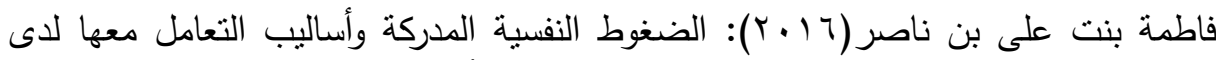

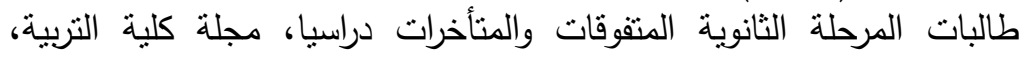


مدحت عبد المحسن الفقى: الاغتراب النفسى وعلاقه بأساليب التعامل وتقدير الذات فى ضوء ألاء

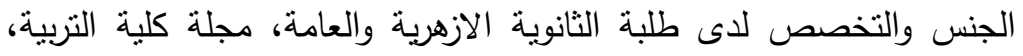

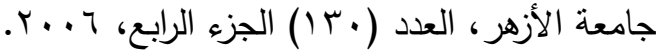

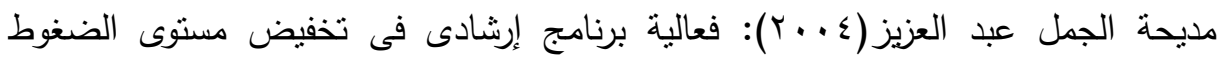

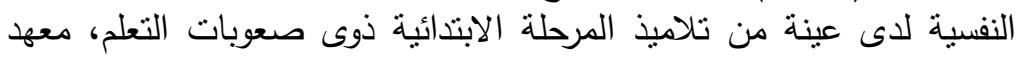

الدراسات العليا للطفولة، قسم الدراسات النفسية والاجتماعية، جامعة الاتية عين شمس.

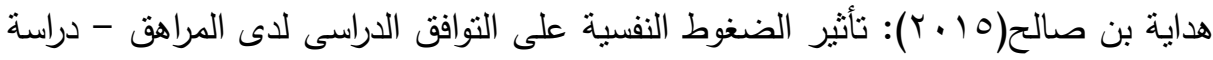

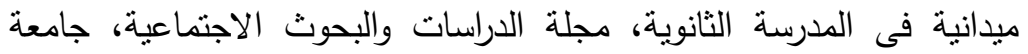
الوادى، (11)

هدى أحمد عبد الل(Y (Y): متغيرات البيئة الاجتماعية الفيزيقية للمتسربين من التعليم

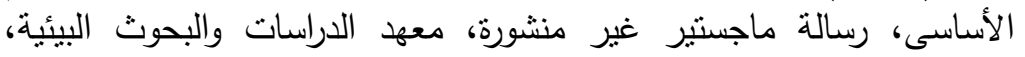
جامعة عين شمس.

Akimbo, J. O. and Ademo, D. A. (2002): Stress at home and work place, Ibadan: Sterling Harden Publishers.

Haley, V. Barker (2009): The relationship between personality, coping styles and stress, anxiety and depression. Master of science in psychology, University of Canterbury.

Kokkinos, C. M. (2007): Job stressors, personality and burnout in primary school teachers, British Journal of Educational Psychology, 77(1), 229-243.

Lyell, Kelly Marie (2012): Social support and psychologjcal adjustment: As study of compensatory relationships. Ann Arbor, MAI51/o4 (E), Aug 2013.

Pocola, Bay ode Isaiah and Ilugbo, Esther A joke (2010): Personality traits as predictors of stress among females teachers in Ostend state teaching service. Edo, journal of counseling. Vol.3, No. 2, 2010. PP. 179 -233.

$$
\text { المجلد الثالث والأربعون، الجزء الأول، سبتمبر 11 ب r }
$$


دعاء محمد العدوي وآخرون

\title{
PSYCHOLOGICAL STRESS FOR SECONDARY \\ STAGE FEMALE STUDENTS AND THEIR RELATIONSHIP TO SOME ENVIRONMENTAL AND SOCIAL VARIABLES
}

\author{
Al-Adawe, Doaa, M. ${ }^{(1)}$; Ahmed, G. Sh. ${ }^{(2)}$ and Hussein, M. A. ${ }^{(3)}$ \\ 1) Institute of Environmental Studies and Research, Ain Shams \\ University 2) Institute of Post Graduate Childhood Studies, Ain Shams \\ University 3) Faculty of Arts, Damietta University
}

\begin{abstract}
The term psychological stress refers to incompatibility with the environment and self-image, and try to reduce incompatibility to avoid emotional tension accompanying the maintain a sense of self and refer to internal or external changes that will lead to a severe, ongoing and more effective response of adolescence Age stages undergoing psychological, emotional and mental changes so this change leads to psychological stress.

The present study aims to reveal the relationship between the psychological pressure of female students and their relationship to certain environmental and social variables. The researcher has identification of a single (300) secondary female student sample, in the age of 14 - 18 years. The researcher used the (descriptive) curriculum, and applied the following measures: (Measure of psychological pressure), (measure of environmental variables), (Social variables measure) and (Preliminary data form) on students in (government schools) and (private schools).

The study has produced some results, among the most important of which is a correlation between pressures Psychological and social variables among secondary students. There is a correlation function between psychological pressures and environmental variables among secondary students. The study has made a series of recommendations,

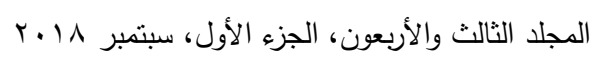


the most important of which is to reduce the psychological stress experienced by female students in terms of developing Curricula and the provision of appropriate material possibilities, taking into account the individual differences among students in the classroom with the need to manage the grade well and understand the needs and desires of female students. The school should work to balance the number of teachers, the size of the school, the number of departments, and the number of female students so that there is no pressure to effect the process of education in accordance with its objectives. 